\title{
Methanol Formation via Oxygen Insertion Chemistry in Ices
}

\section{Citation}

Bergner, Jennifer B., Karin I. Öberg, and Mahesh Rajappan. 2017. Methanol Formation via Oxygen Insertion Chemistry in Ices. The Astrophysical Journal 845, no. 1: 29.

\section{Permanent link}

http://nrs.harvard.edu/urn-3:HUL.InstRepos:41140167

\section{Terms of Use}

This article was downloaded from Harvard University's DASH repository, and is made available under the terms and conditions applicable to Open Access Policy Articles, as set forth at http:// nrs.harvard.edu/urn-3:HUL.InstRepos:dash.current.terms-of-use\#OAP

\section{Share Your Story}

The Harvard community has made this article openly available.

Please share how this access benefits you. Submit a story.

\section{Accessibility}


Draft VERSion July 6, 2017

Preprint typeset using LATEX style AASTeX6 v. 1.0

\title{
METHANOL FORMATION VIA OXYGEN INSERTION CHEMISTRY IN ICES
}

\author{
Jennifer B. Bergner ${ }^{1}$, KARIn I. ÖBerg ${ }^{2}$, MAhesh RAJAPPAn ${ }^{2}$
}

\footnotetext{
${ }^{1}$ Harvard University Department of Chemistry and Chemical Biology, 10 Oxford Street, Cambridge, MA 02138, USA

${ }^{2}$ Harvard-Smithsonian Center for Astrophysics, 60 Garden Street, Cambridge, MA 02138, USA
}

\begin{abstract}
We present experimental constraints on the insertion of oxygen atoms into methane to form methanol in astrophysical ice analogs. In gas-phase and theoretical studies this process has previously been demonstrated to have a very low or non-existent energy barrier, but the energetics and mechanisms have not yet been characterized in the solid state. We use a deuterium UV lamp filtered by a sapphire window to selectively dissociate $\mathrm{O}_{2}$ within a mixture of $\mathrm{O}_{2}: \mathrm{CH}_{4}$ and observe efficient production of $\mathrm{CH}_{3} \mathrm{OH}$ via $\mathrm{O}\left({ }^{1} \mathrm{D}\right)$ insertion. $\mathrm{CH}_{3} \mathrm{OH}$ growth curves are fit with a kinetic model, and we observe no temperature dependence of the reaction rate constant at temperatures below the oxygen desorption temperature of $25 \mathrm{~K}$. Through an analysis of side products we determine the branching ratio of icephase oxygen insertion into $\mathrm{CH}_{4}: \sim 65 \%$ of insertions lead to $\mathrm{CH}_{3} \mathrm{OH}$ with the remainder leading instead to $\mathrm{H}_{2} \mathrm{CO}$ formation. There is no evidence for $\mathrm{CH}_{3}$ or $\mathrm{OH}$ radical formation, indicating that the fragmentation is not an important channel and that insertions typically lead to increased chemical complexity. $\mathrm{CH}_{3} \mathrm{OH}$ formation from $\mathrm{O}_{2}$ and $\mathrm{CH}_{4}$ diluted in a $\mathrm{CO}$-dominated ice similarly shows no temperature dependence, consistent with expectations that insertion proceeds with a small or nonexistent barrier. Oxygen insertion chemistry in ices should therefore be efficient under low-temperature ISM-like conditions, and could provide an important channel to complex organic molecule formation on grain surfaces in cold interstellar regions such as cloud cores and protoplanetary disk midplanes.
\end{abstract}

\section{INTRODUCTION}

Complex organic molecules (COMs) have been detected towards star-forming regions at all stages of evolution, including molecular clouds, protostellar hot cores, envelopes, and outflows, and protoplanetary disks (e.g. Blake et al. 1987; Bottinelli et al. 2004; Arce et al. 2008; Öberg et al. 2010, 2015). It is of great interest to understand the rich chemistry that feeds the formation and destruction of these molecules in the interstellar medium (ISM) in order to constrain the chemical inventories available for pre-biotic chemistry as solar systems develop. To explain COM production, current astrochemical models typically rely on grain-surface radical recombination chemistry that becomes active in lukewarm $(\sim 30 \mathrm{~K})$ ices (Garrod et al. 2008; Herbst \& van Dishoeck 2009). However, observations of COMs towards very cold interstellar environments such as prestellar cores (Öberg et al. 2010; Bacmann et al. 2012; Cernicharo et al. 2012, e.g.) indicate that a cold pathway to complex molecule formation must also be active.

A central challenge to building chemical complexity at low temperatures is the incorporation of several heavy elements into molecules. To address this, many experimental studies have focused on the hydrogenation of unsaturated oxygen-bearing molecules. Repeated hy- drogenation of $\mathrm{CO}$ has been shown to be efficient and leads to the production of the stable molecules $\mathrm{H}_{2} \mathrm{CO}$ and $\mathrm{CH}_{3} \mathrm{OH}$ (Watanabe \& Kouchi 2002; Fuchs et al. 2009):

$$
\mathrm{CO} \underset{(1)}{\stackrel{\mathrm{H}}{\longrightarrow}} \mathrm{HCO} \underset{(2)}{\stackrel{\mathrm{H}}{\longrightarrow}} \mathrm{H}_{2} \mathrm{CO} \underset{(3)}{\stackrel{\mathrm{H}}{\longrightarrow}} \mathrm{H}_{3} \mathrm{CO} \underset{(4)}{\stackrel{\mathrm{H}}{\longrightarrow}} \mathrm{CH}_{3} \mathrm{OH}
$$

In addition, $\mathrm{H}$ atom bombardment of $\mathrm{CO}$ ices has been recently shown to form even more complex molecules: $\mathrm{H}$ atom abstractions along the $\mathrm{CO}$ hydrogenation pathway (1) lead to enhanced populations of radical species, which can recombine to form larger COMs (Fedoseev et al. 2015; Chuang et al. 2016). However, this recombination chemistry requires diffusion of relatively heavy radical species, which in interstellar ices are not expected to be mobile at low temperatures.

Here, we present experiments demonstrating an oxygen insertion mechanism as an alternative pathway to $\mathrm{COM}$ formation at low temperatures, using the test case of $\mathrm{CH}_{3} \mathrm{OH}$ formation from $\mathrm{O}$ insertion into $\mathrm{CH}_{4}$. Unlike radical recombination pathways, oxygen insertion does not require diffusion of heavy species. The ability to convert hydrocarbons directly to COMs represents a novel channel to explain observed COM abundances.

The gas-phase insertion of excited $\mathrm{O}\left({ }^{1} \mathrm{D}\right)$ into $\mathrm{CH}_{4}$ has been well-studied: initially, vibrationally excited 
$\mathrm{CH}_{3} \mathrm{OH}$ is formed, and at sufficiently high pressures can be collisionally stabilized; otherwise, the molecule fragments into the radical products $\mathrm{CH}_{3}+\mathrm{OH}$ (DeMore \& Raper 1967; Lin \& DeMore 1973). In the gas phase, therefore, insertions are typically net destructive and lead to smaller rather than larger molecules. Gas-phase oxygen insertion has been shown experimentally to be essentially barrierless (e.g. DeMore \& Raper 1967), and indeed theoretical studies suggest a small $\sim 280 \mathrm{~K}$ barrier (Yu \& Muckerman 2004).

Oxygen insertion has also been qualitatively demonstrated in condensed systems. In Appelman et al. (1989), HOF was photolyzed within a $\mathrm{CH}_{4}$ matrix under high vacuum $\left(10^{-7}\right.$ Torr $)$ conditions. Parnis et al. (1993) and Lugez et al. (1994) both studied oxygen insertion into $\mathrm{CH}_{4}$ within Ar matrices, using photolysis of $\mathrm{N}_{2} \mathrm{O}$ and $\mathrm{O}_{3}$ respectively for $\mathrm{O}\left({ }^{1} \mathrm{D}\right)$ atom generation. Each of these studies qualitatively demonstrated $\mathrm{CH}_{3} \mathrm{OH}$ formation via oxygen insertion in the solid state. However, to date there is no quantitative or mechanistic description of this process. Moreover, the ice compositions in these previous studies are not astrophysically realistic. In order to evaluate the extent to which oxygen insertion can lead to chemical complexity in the ISM, a detailed understanding of how this process occurs in astrophysical ice analogs is required. In particular, it is essential to determine the energetic feasibility under ISM-like conditions, and the efficiency of $\mathrm{CH}_{3} \mathrm{OH}$ formation compared to fragmentation and other product formation.

$\mathrm{O}\left({ }^{1} \mathrm{D}\right)$ atoms, which are required for this insertion process, are in the first electronically excited state with energies $\sim 2 \mathrm{eV}$ higher than the ground state $\mathrm{O}\left({ }^{3} \mathrm{P}\right) . \mathrm{O}\left({ }^{1} \mathrm{D}\right)$ production has been demonstrated by UV photolysis of a number of molecules which should be abundant in interstellar ice mantles, including $\mathrm{O}_{2}, \mathrm{CO}_{2}, \mathrm{O}_{3}$, and $\mathrm{H}_{2} \mathrm{O}$, as well as electron impact of $\mathrm{O}_{2}$ and $\mathrm{CO}_{2}$ (Lee et al. 1977; Slanger \& Black 1971; DeMore \& Raper 1966; Stief et al. 1975; Cosby 1993; Kedzierski et al. 2013). $\mathrm{CO}_{2}$ and $\mathrm{H}_{2} \mathrm{O}$ are of particular importance, as $\mathrm{H}_{2} \mathrm{O}$ is the main constituent of interstellar ices and $\mathrm{CO}_{2}$ is typically present at abundances of $\sim 10-30 \%$ with respect to $\mathrm{H}_{2} \mathrm{O}$ (Öberg et al. 2011). Photolysis of $\mathrm{CO}_{2}$ follows the dissociation channel to $\mathrm{O}\left({ }^{1} \mathrm{D}\right)+\mathrm{CO}\left({ }^{1} \Sigma^{+}\right)$between $120 \mathrm{~nm}$ and $170 \mathrm{~nm}$, with measured efficiencies of $94 \%$ and $100 \%$ at $157 \mathrm{~nm}$ and $147 \mathrm{~nm}$ respectively (Zhu \& Gordon 1990; Slanger \& Black 1971). From 105nm-145nm, $\mathrm{H}_{2} \mathrm{O}$ dissociates to $\mathrm{H}_{2}+\mathrm{O}\left({ }^{1} \mathrm{D}\right.$ ) with an efficiency of $\sim 10 \%$ (Ung 1974; Stief et al. 1975; Slanger \& Black 1982). Importantly, for both $\mathrm{CO}_{2}$ and $\mathrm{H}_{2} \mathrm{O}, \mathrm{O}\left({ }^{1} \mathrm{D}\right)$ can be generated upon exposure to Lyman- $\alpha$ irradiation $(121.6 \mathrm{~nm})$, which dominates the UV spectrum in cloud cores and protoplanetary disks (e.g. Öberg 2016). Therefore, dissociation of common oxygen-bearing molecules in ice mantles should produce these excited oxygen atoms, which may then insert into neighboring hydrocarbons within the ice.

To assess the energetics and mechanism of this reaction scheme in astrophysical ice analogs, we selectively dissociate $\mathrm{O}_{2}$ within mixed $\mathrm{O}_{2}: \mathrm{CH}_{4}$ ices and $\mathrm{O}_{2}: \mathrm{CH}_{4}: \mathrm{CO}$ ices. In Section 2, we describe the experimental apparatus and procedures. Section 3 details the data analysis techniques used, and Section 4 presents the results. In Section 5 we discuss the reaction network and mechanisms in this system, as well as the astrophysical implications of this process.

\section{EXPERIMENTAL DETAILS}

We use the ulta-high vacuum experiment described in detail in Lauck et al. (2015). The chamber is evacuated to a base pressure of $\sim 5 \times 10^{-10}$ Torr. A closedcycle He cryostat cools a CsI substrate window to temperatures as low as 9K. Temperature is monitored by a temperature controller (LakeShore 335) with an estimated accuracy of $2 \mathrm{~K}$ and a relative uncertainty of $0.1 \mathrm{~K}$. Ices are typically grown on the substrate by introduction of gases through a $4.8 \mathrm{~mm}$ diameter dosing pipe at 0.7 inches from the substrate. For co-deposition experiments, two separate dosing pipes at $\sim 1.2$ inches from the substrate were used to introduce gases. Experiments were performed using the following gases: $\mathrm{CH}_{4}(99.9 \%$ purity, Aldrich), ${ }^{13} \mathrm{CH}_{4}$ (99\%, Aldrich), $\mathrm{CD}_{4}$ (99\%, Aldrich), ${ }^{16} \mathrm{O}_{2}$ (99.98\%, Aldrich), ${ }^{18} \mathrm{O}_{2}$ (97\%, Aldrich), Ar (99.95\%, Aldrich), and CO (99.95\%, Aldrich). To obtain mixtures, gases were combined in a differentially pumped gas line with a base pressure $\sim 10^{-4}$ Torr. A Fourier transform infrared spectrometer (Bruker Vertex $70 \mathrm{v}$ ) in transmission mode was used to measure infraredactive molecules in the ice. A quadrupole mass spectrometer (Pfeiffer QMG 220M1) continuously monitored the gas-phase species present in the chamber.

To selectively dissociate $\mathrm{O}_{2}$ within a $\mathrm{CH}_{4}$ : $\mathrm{O}_{2}$ mixture, we irradiate the ice samples with a $\mathrm{H}_{2} \mathrm{D}_{2}$ lamp (Hamamatsu L11798) filtered by a 0.08" thick sapphire window (MPF Products, Inc.) Figure 1a shows the spectral distribution of the UV lamp overlaid with the transmittance spectrum of sapphire with a similar thickness ${ }^{1}$ and the UV absorption cross-sections for both $\mathrm{CH}_{4}$ and $\mathrm{O}_{2}$ (Cruz-Diaz et al. 2014b). The convolution of lamp intensity, sapphire transmittance, and absorption crosssection for each species is shown as the "effective" crosssection in Figure 1b. This represents the relative absorption of each molecule under the irradiation conditions of the present experiment. The absorption of $\mathrm{CH}_{4}$ is negligible due to the cutoff of the sapphire window, while $\mathrm{O}_{2}$

$1 \mathrm{http}: / /$ resources.montanainstruments.com/help/window-
materials 


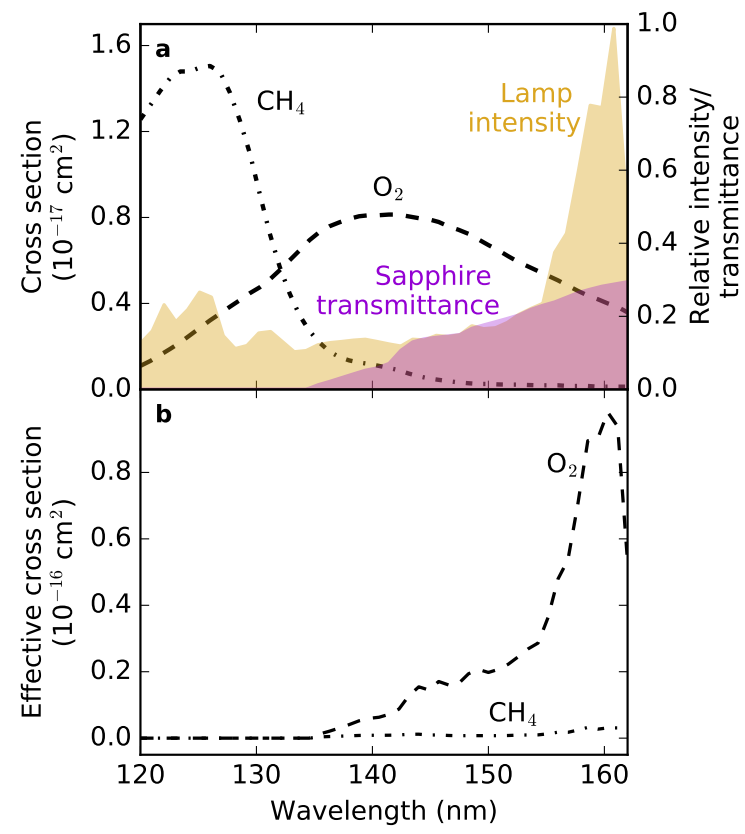

Figure 1. a: $\mathrm{CH}_{4}$ (black dash-dot) and $\mathrm{O}_{2}$ (black dash) UV absorption cross-sections (Cruz-Diaz et al. 2014b) overlaid with the $\mathrm{H}_{2} \mathrm{D}_{2}$ UV lamp output spectrum (gold) and sapphire transmission spectrum (purple). b: The effective absorption cross-sections for $\mathrm{CH}_{4}$ and $\mathrm{O}_{2}$ resulting from the convolution of each absorption cross-section with the relative lamp intensity and window transmittance spectra.

still has a large absorption profile which is dominated by the $160.8 \mathrm{~nm}$ Lyman band of the $\mathrm{H}_{2} \mathrm{D}_{2}$ lamp. The photoproducts of $\mathrm{O}_{2}$ in this wavelength regime are wellcharacterized: upon exposure to light at wavelengths from $140-175 \mathrm{~nm}, \mathrm{O}_{2}$ dissociates into $\mathrm{O}\left({ }^{3} \mathrm{P}\right)+\mathrm{O}\left({ }^{1} \mathrm{D}\right)$ with an efficiency of unity (Lee et al. 1977).

All experimental details are summarized in Table 1. We define different groups of experiments, each varying with respect to the Fiducial category as indicated: (IFiducial) ${ }^{16} \mathrm{O}_{2}:{ }^{13} \mathrm{CH}_{4} \sim 1.4: 1,50 \mathrm{ML}$ total ice thickness; (II) 20ML thickness; (III) $\sim 0.2: 1$ ratio; (IV) capping layer of argon; (V) 90ML thickness; (VI): ${ }^{12} \mathrm{CD}_{4}:{ }^{18} \mathrm{O}_{2}$; (VII) other isotopologues (qualitative analysis only); (VIII) $\mathrm{CO}:{ }^{13} \mathrm{CH}_{4}:{ }^{16} \mathrm{O}_{2}$ 4:1:1, 125ML thickness; (IX): $\mathrm{CO}:{ }^{13} \mathrm{CH}_{4}:{ }^{16} \mathrm{O}_{2}$ 7:1:1, 170ML thickness; (X): control experiments- only 1 reactant.

The experimental procedure for groups I-VII involved a single deposition of a mixture of $\mathrm{CH}_{4}$ and $\mathrm{O}_{2}$; for groups VIII and IX, separate dosing tubes were used to co-deposit $\mathrm{CO}$ and a $\mathrm{CH}_{4}: \mathrm{O}_{2}$ mixture. In all cases, dosing was performed at $9 \mathrm{~K}$, followed by a 2 hour sample irradiation at a set temperature at an angle of $45^{\circ}$ by the $\mathrm{H}_{2} \mathrm{D}_{2}$ lamp. During irradiation, IR scans were taken every 3 minutes. Following irradiation, a temperature programmed desorption (TPD) was performed by ramping the sample temperature at a rate of $2 \mathrm{~K} / \mathrm{min}$ to $200 \mathrm{~K}$. During the temperature ramp, IR scans were taken every 2 minutes and desorbing species were monitored with the QMS.

Table 1. Experiment summary

\begin{tabular}{lccccc}
\hline \hline Experiment & Group & $\begin{array}{c}\text { Irradiation } \\
\text { temp (K) }\end{array}$ & Ice composition & Ratio & $\begin{array}{c}\text { Total thickness } \\
\text { (ML) }\end{array}$ \\
\hline 1 & I & 9 & ${ }^{16} \mathrm{O}_{2}:{ }^{13} \mathrm{CH}_{4}$ & $1.3: 1$ & 53 \\
2 & I & 9 & ${ }^{16} \mathrm{O}_{2}:{ }^{13} \mathrm{CH}_{4}$ & $1.8: 1$ & 52 \\
3 & I & 14 & ${ }^{16} \mathrm{O}_{2}:{ }^{13} \mathrm{CH}_{4}$ & $1.4: 1$ & 53 \\
4 & I & 19 & ${ }^{16} \mathrm{O}_{2}:{ }^{13} \mathrm{CH}_{4}$ & $1.3: 1$ & 51 \\
5 & I & 24 & ${ }^{16} \mathrm{O}_{2}:{ }^{13} \mathrm{CH}_{4}$ & $1.4: 1$ & 50 \\
6 & I & 25 & ${ }^{16} \mathrm{O}_{2}:{ }^{13} \mathrm{CH}_{4}$ & $1.4: 1$ & 54 \\
7 & II & 9 & ${ }^{16} \mathrm{O}_{2}:{ }^{13} \mathrm{CH}_{4}$ & $0.9: 1$ & 18 \\
8 & II & 14 & ${ }^{16} \mathrm{O}_{2}:{ }^{13} \mathrm{CH}_{4}$ & $1.6: 1$ & 23 \\
9 & II & 19 & ${ }^{16} \mathrm{O}_{2}:{ }^{13} \mathrm{CH}_{4}$ & $1.3: 1$ & 19 \\
10 & III & 9 & ${ }^{16} \mathrm{O}_{2}:{ }^{13} \mathrm{CH}_{4}$ & $0.2: 1$ & 26 \\
11 & III & 19 & ${ }^{16} \mathrm{O}_{2}:{ }^{13} \mathrm{CH}_{4}$ & $0.2: 1$ & 23 \\
12 & III & 24 & ${ }^{16} \mathrm{O}_{2}:{ }^{13} \mathrm{CH}_{4}$ & $0.2: 1$ & 23 \\
$13^{\mathrm{a}}$ & IV & 9 & ${ }^{16} \mathrm{O}_{2}:{ }^{13} \mathrm{CH}_{4}$ & $1.2: 1$ & 38 \\
14 & V & 9 & ${ }^{16} \mathrm{O}_{2}:{ }^{13} \mathrm{CH}_{4}$ & $1.6: 1$ & 92 \\
15 & V & 9 & ${ }^{16} \mathrm{O}_{2}:{ }^{13} \mathrm{CH}_{4}$ & $1.6: 1$ & 87 \\
$16^{\mathrm{a}}$ & VI & 9 & ${ }^{18} \mathrm{O}_{2}:{ }^{12} \mathrm{CD}_{4}$ & $1.5: 1$ & 37 \\
17 & VI & 9 & ${ }^{18} \mathrm{O}_{2}:{ }^{12} \mathrm{CD}_{4}$ & $1.9: 1$ & 66 \\
18 & VI & 19 & ${ }^{18} \mathrm{O}_{2}:{ }^{12} \mathrm{CD}_{4}$ & $1.7: 1$ & 59 \\
& & & & & \\
\hline
\end{tabular}


Table 1 (continued)

\begin{tabular}{|c|c|c|c|c|c|}
\hline Experiment & Group & $\begin{array}{l}\text { Irradiation } \\
\text { temp }(\mathrm{K})\end{array}$ & Ice composition & Ratio & $\begin{array}{c}\text { Total thickness } \\
\text { (ML) }\end{array}$ \\
\hline $19^{\mathrm{a}}$ & VII & 9 & ${ }^{18} \mathrm{O}_{2}:{ }^{13} \mathrm{CH}_{4}$ & $0.8: 1$ & 32 \\
\hline 20 & VII & 9 & ${ }^{16} \mathrm{O}_{2}:{ }^{12} \mathrm{CH}_{4}$ & $1.5: 1$ & 55 \\
\hline 21 & VIII & 9 & ${ }^{12} \mathrm{CO}:{ }^{16} \mathrm{O}_{2}:{ }^{13} \mathrm{CH}_{4}$ & $4.3: 1.1: 1$ & 125 \\
\hline 22 & VIII & 19 & ${ }^{12} \mathrm{CO}:{ }^{16} \mathrm{O}_{2}:{ }^{13} \mathrm{CH}_{4}$ & $4.5: 1.1: 1$ & 127 \\
\hline 23 & VIII & 19 & ${ }^{12} \mathrm{CO}:{ }^{16} \mathrm{O}_{2}:{ }^{13} \mathrm{CH}_{4}$ & $4.4: 1.1: 1$ & 125 \\
\hline 24 & IX & 9 & ${ }^{12} \mathrm{CO}:{ }^{16} \mathrm{O}_{2}:{ }^{13} \mathrm{CH}_{4}$ & $6.9: 1.0: 1$ & 172 \\
\hline 25 & IX & 14 & ${ }^{12} \mathrm{CO}:{ }^{16} \mathrm{O}_{2}:{ }^{13} \mathrm{CH}_{4}$ & $6.8: 1.0: 1$ & 172 \\
\hline 26 & IX & 19 & ${ }^{12} \mathrm{CO}:{ }^{16} \mathrm{O}_{2}:{ }^{13} \mathrm{CH}_{4}$ & $7.0: 1.0: 1$ & 174 \\
\hline 27 & $\mathrm{X}$ & 9 & ${ }^{13} \mathrm{CH}_{4}$ & - & 15 \\
\hline 28 & $\mathrm{X}$ & 9 & ${ }^{16} \mathrm{O}_{2}$ & - & 23 \\
\hline
\end{tabular}

$a_{\text {with Ar top layer }}$

See text for Group designations

\section{DATA ANALYSIS}

\section{1. $\mathrm{O}_{2}$ thickness determination}

Since $\mathrm{O}_{2}$ is infrared inactive, we quantify the $\mathrm{O}_{2}$ dose by calibrating the time-integrated QMS signal to the IR-determined $\mathrm{CH}_{4}$ dose as in Fayolle et al. (2013):

$$
N_{O_{2}}=N_{C H_{4}} \frac{\int I_{O_{2}^{+}} d t}{\int I_{C H_{4}^{+}} d t} \frac{\sigma_{C H_{4}^{+}}}{\sigma_{O_{2}^{+}}} .
$$

Here, $N_{x}$ is the column density of species $x, \int I_{x} d t$ is the time-integrated QMS intensity of each molecule's dominant ion, and $\sigma_{x}$ is the gas-phase electron impact ionization cross-section of each molecular ion at $70 \mathrm{eV}$. The QMS mass signals $m / z 17,20,32$, and 36 are used to trace ${ }^{13} \mathrm{CH}_{4}, \mathrm{CD}_{4},{ }^{16} \mathrm{O}_{2}$, and ${ }^{18} \mathrm{O}_{2}$ respectively; these masses should not be contaminated by signal from any other molecule. $\mathrm{O}_{2}$ and $\mathrm{CH}_{4}$ cross-sections are taken from Straub et al. (1996) and Straub et al. (1997) respectively. The average value of $N_{\mathrm{CH}_{4}} / \int I_{\mathrm{CH}_{4}^{+}} d t$ from all experiments was used to convert to $\mathrm{O}_{2}$ doses; based on variations between experiments, we expect an $\mathrm{O}_{2}$ dose uncertainty of about $30 \%$. The $\mathrm{CH}_{4}$ thickness uncertainty is $\sim 20 \%$, arising mainly due to the uncertainty in band strength.

\section{2. $U V$ flux}

The photon flux from the UV lamp was measured with a NIST calibrated AXUV-100G photo-diode at the sample holder to be $\sim 1.4 \times 10^{13}$ photons $\mathrm{cm}^{-2} \mathrm{~s}^{-1}$, with a measurement uncertainty of $\sim 5 \%$ for the wavelengths of interest in this work. For a 2-hour irradiation, this results in a total fluence of $1 \times 10^{17} \mathrm{~cm}^{-2}$. To ensure that UV photons penetrate the entire ice sample, we calculate the attenuation of photons for experiments of different ice thickness. The photon attenuation is calculated at $160.8 \mathrm{~nm}$, since this represents the peak of the "effective" cross-section (Section 2), using the formula

$$
N_{X}=-\frac{1}{\sigma_{X}(\lambda)} \ln \frac{\mathrm{I}_{\mathrm{t}}(\lambda)}{\mathrm{I}_{0}(\lambda)}
$$

where $N_{X}$ is the column density of molecule $\mathrm{X}$ (molecule $\left.\mathrm{cm}^{-2}\right), \sigma_{X}(\lambda)$ is the UV absorption cross-section, and $\mathrm{I}_{\mathrm{t}}(\lambda)$ and $\mathrm{I}_{0}(\lambda)$ are the transmitted and incident intensities, respectively. We assume the standard monolayer coverage of $10^{15}$ molecules $\mathrm{cm}^{-2}$ and cross-sections $\sigma_{O_{2}}(160.8 \mathrm{~nm})=3.9 \times 10^{-18} \mathrm{~cm}^{2}$ and $\sigma_{C O}(160.8 \mathrm{~nm})=$ $0.9 \times 10^{-18} \mathrm{~cm}^{2}$ (Cruz-Diaz et al. 2014a,b). For $\mathrm{O}_{2}$ ice, 15,35 , and $65 \mathrm{ML}$ will absorb $6 \%, 13 \%$, and $22 \%$ of photons respectively. For CO ice, 85 and $135 \mathrm{ML}$ will absorb $7 \%$ and $11 \%$ of photons respectively. Therefore, photon attenuation is small and should not impact the experimental results even for the thickest $\mathrm{O}_{2}$ and $\mathrm{CO}$ ices.

\subsection{IR spectra and growth curves}

IR spectra were used to determine the initial ice column densities of $\mathrm{CH}_{4}$ as well as the growth of products during irradiation. Each spectrum is averaged over 128 interferograms and takes approximately 2 minutes to complete. Column densities of each species were calculated using the integrated area of IR features:

$$
N_{i}=\frac{2.3 \int \tau_{i}(\nu) d \nu}{A_{i}},
$$

where $N_{i}$ is column density (molecule $\mathrm{cm}^{-2}$ ), $\int \tau_{i}(\nu) d \nu$ is the integrated area of the IR band (absorbance units), and $A_{i}$ is the band strength in optical depth units. The standard monolayer coverage of $10^{15}$ molecules $\mathrm{cm}^{-2}$ was assumed. 
Table 2. IR band strengths

\begin{tabular}{|c|c|c|c|c|}
\hline \multirow[t]{2}{*}{ Molecule } & \multirow[t]{2}{*}{ Mode } & \multicolumn{2}{|c|}{ Line center $\left(\mathrm{cm}^{-1}\right)$} & \multirow{2}{*}{$\begin{array}{c}A \\
\left(\mathrm{~cm} \mathrm{molec}^{-1}\right)\end{array}$} \\
\hline & & $\left({ }^{13} \mathrm{C} /{ }^{16} \mathrm{O} / \mathrm{H}\right)$ & $\left({ }^{12} \mathrm{C} /{ }^{18} \mathrm{O} / \mathrm{D}\right)$ & \\
\hline $\mathrm{CH}_{4}$ & $\nu_{4}$ bend & 1291 & 989 & $8.4 \times 10^{-18}(a)$ \\
\hline $\mathrm{CH}_{3} \mathrm{OH}$ & $\nu_{8} \mathrm{CO} \operatorname{str}$ & 1008 & 952 & $1.8 \times 10^{-17}(a)$ \\
\hline $\mathrm{O}_{3}$ & $\nu_{3}$ a-str & 1034 & 975 & $8.8 \times 10^{-18}(b)$ \\
\hline $\mathrm{CO}$ & str & 2092 & & $1.1 \times 10^{-17}(a)$ \\
\hline $\mathrm{CO}_{2}$ & $\nu_{3}$ a-str & 2276 & & $1.3 \times 10^{-16}(a)$ \\
\hline \multirow[t]{2}{*}{$\mathrm{H}_{2} \mathrm{CO}$} & $\nu_{2} \mathrm{CO} \operatorname{str}$ & 1683 & & $9.6 \times 10^{-18}(a)$ \\
\hline & $\nu_{3} \mathrm{CH}_{2}$ sc. & 1498 & & $3.9 \times 10^{-18}(a)$ \\
\hline $\mathrm{H}_{2} \mathrm{O}$ & $\nu_{2}$ bend & 1652 & & $1.1 \times 10^{-17}(a)$ \\
\hline
\end{tabular}

Product growth curves can only be measured for ${ }^{13} \mathrm{CH}_{4}:{ }^{16} \mathrm{O}_{2}$ and ${ }^{12} \mathrm{CD}_{4}:{ }^{18} \mathrm{O}_{2}$ mixtures (Groups I-VI and VIII-IX), as other isotopologue combinations have overlapping $\mathrm{O}_{3}$ and $\mathrm{CH}_{3} \mathrm{OH}$ infrared features. IR band centers and strengths used for quantifying molecule abundances are listed in Table 2.

$\mathrm{O}_{3}$ column densities are highly uncertain since only RAIRS band strengths were available in the literature. However, absolute $\mathrm{O}_{3}$ measurements are not required for quantifying the reaction between $\mathrm{O}$ atoms and $\mathrm{CH}_{4}$. To estimate the ozone abundance, we assume that the ratio between RAIRS and transmission band strengths is consistent within an experiment (e.g. Ioppolo et al. 2008). We therefore scale the RAIRS band strength of $\mathrm{O}_{3}$ reported in Loeffler et al. (2006) by the ratio of the transmission and RAIRS band strengths for the $\mathrm{H}_{2} \mathrm{O}$ $\nu_{2}$ bending mode ( 1.4; Bouilloud et al. 2015; Loeffler et al. 2006).

For $\mathrm{CH}_{3} \mathrm{OH}$, the direct product of $\mathrm{O}$ insertion into $\mathrm{CH}_{4}$, the strongest feature is the $\nu_{8}$ band. Due to the proximity of the $\mathrm{O}_{3} \nu_{3}$ band, both features were fit simultaneously with Gaussian profiles. Each feature is well-fit by a double Guassian; thus, for each spectrum we fit four Gaussians as seen in Figure 2a. Fitting is done using the python emcee package (Foreman-Mackey et al. 2013). In addition to the four Gaussian profiles, we simultaneously fit a local linear baseline term as part of the overall fit. This enables us to incorporate any uncertainties that arise from the choice of baseline into subsequent analysis. Figure 9 in Appendix A shows an example corner plot displaying the degree of parameter covariance as well as the fit convergence.

\subsection{Kinetic modeling}

The reaction steps leading to methanol formation are:

$$
\begin{array}{r}
\mathrm{O}_{2} \underset{h \nu}{\stackrel{k_{p d}}{\longrightarrow}} \mathrm{O}\left({ }^{3} \mathrm{P}\right)+\mathrm{O}\left({ }^{1} \mathrm{D}\right) \\
\mathrm{O}\left({ }^{1} \mathrm{D}\right)+\mathrm{CH}_{4} \stackrel{k_{r}}{\longrightarrow} \mathrm{CH}_{3} \mathrm{OH}
\end{array}
$$

where $\mathrm{k}_{p d}$ is the photodissociation rate of $\mathrm{O}_{2}$ and $k_{r}$ is the rate of oxygen insertion to form methanol. In addition to formation via $\mathrm{O}$ insertion, $\mathrm{CH}_{3} \mathrm{OH}$ can also be photo-dissociated by UV light in this wavelength range. To account for potential $\mathrm{CH}_{3} \mathrm{OH}$ loss we include a destruction term in the kinetic model:

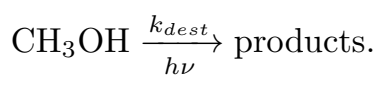

As detailed in previous work, there are numerous possible products of $\mathrm{CH}_{3} \mathrm{OH}$ processing (Bennett et al. 2007; Öberg et al. 2009). For the purposes of fitting growth curves, we are mainly interested in the loss of $\mathrm{CH}_{3} \mathrm{OH}$, and discuss the potential formation of other products in more detail in Section 4. We note that $\mathrm{CH}_{3} \mathrm{OH}$ could also be consumed by other mechanisms such as $\mathrm{H}$ abstractions, however we assume that photodissociation is the dominant destruction mechanism. Incorporating other pathways would require modeling the entire system simultaneously, which is not practical given difficulties in measuring column densities of each product throughout the experiment.

From Reactions 6 and 7 we obtain the integrated rate law describing $\mathrm{CH}_{3} \mathrm{OH}$ formation:

$$
\left[\mathrm{CH}_{3} \mathrm{OH}\right](t)=\frac{k_{r} \mathrm{~N}_{\mathrm{ss}}\left(e^{-k_{\text {dest }} t}-e^{-k_{r} t}\right)}{k_{r}-k_{\text {dest }}}
$$

where $\mathrm{N}_{\mathrm{ss}}$ is a proportionality factor representing the steady-state abundance. We have assumed that the timescales of $\mathrm{O}\left({ }^{1} \mathrm{D}\right)$ atom formation and destruction are much faster than the reaction timescale, and therefore 

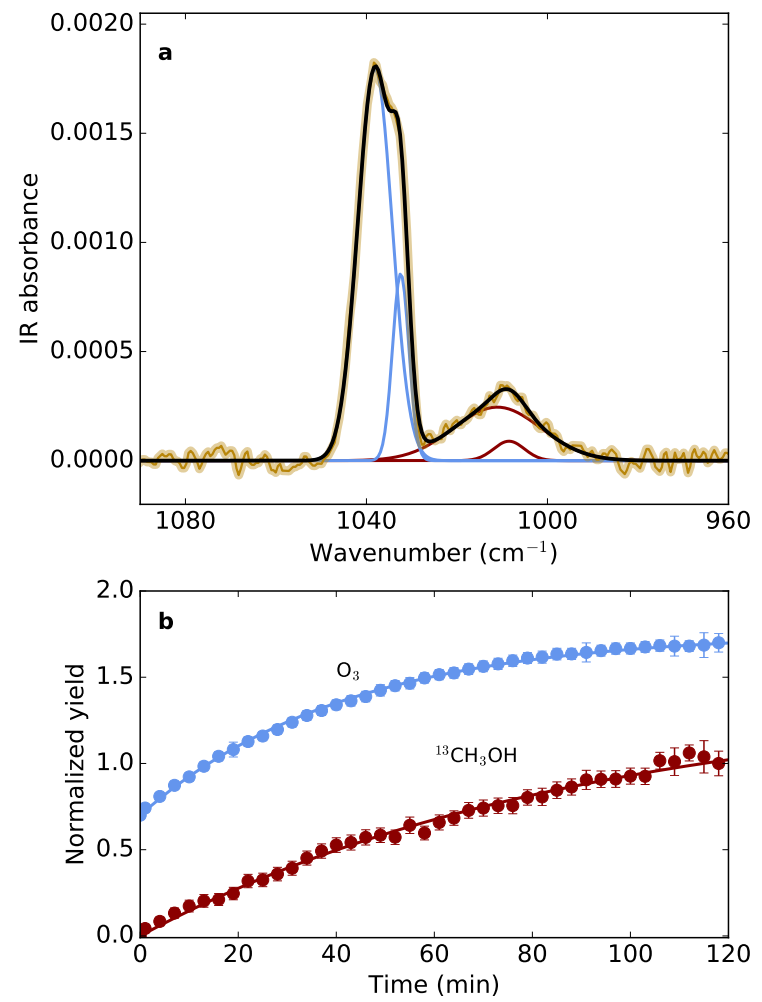

Figure 2. a: Example fit to infrared bands of $\mathrm{O}_{3}$ at $1034 \mathrm{~cm}^{-1}$ and ${ }^{13} \mathrm{CH}_{3} \mathrm{OH}$ at $1008 \mathrm{~cm}^{-1}$. The experimental spectrum is shown in gold and the total fit in black, with individual Gaussians in blue for ozone and red for methanol. b: Scatter points show experimental growth curves for $\mathrm{O}_{3}$ (blue; offset) and ${ }^{13} \mathrm{CH}_{3} \mathrm{OH}$ (red). Kinetic fits are shown as solid lines. Both panels show results from Experiment 3. Product yield has been normalized by the column density at the end of 2 hours of irradiation.

the photodissociation kinetics of $\mathrm{O}_{2}$ (Reaction 5) do not contribute to the overall growth rate. Indeed, typical $\mathrm{CH}_{3} \mathrm{OH}$ formation rates are on the order of $10^{-4} \mathrm{ML}$ $\mathrm{s}^{-1}$, while the timescale for $\mathrm{O}$ formation $\left(\sim \sigma_{\mathrm{O}_{2}} \mathrm{x}\right.$ flux $\mathrm{x} \mathrm{N}_{\mathrm{O}_{2}}$ ) is an order of magnitude faster, and the rate constant for $\mathrm{O}\left({ }^{1} \mathrm{D}\right)$ relaxation to $\mathrm{O}\left({ }^{3} \mathrm{P}\right)$ in solids is on the order of $\sim 1 \mathrm{~s}^{-1}$ (Mohammed 1990).

For fitting Equation 8 to growth curves, we assume that the rate constant for photodestruction of $\mathrm{CH}_{3} \mathrm{OH}$ is equal to that of photon absorption, or $\sigma_{\mathrm{CH}_{3} \mathrm{OH}} \mathrm{x} f l u x$. $\sigma_{\mathrm{CH}_{3} \mathrm{OH}}$ is taken from Cruz-Diaz et al. (2014a) to be 2.9 $\mathrm{x} 10^{-18} \mathrm{~cm}^{2}$ at $160.8 \mathrm{~nm}$ for a total absorption rate $=$ $4.1 \times 10^{-5} \mathrm{~s}^{-1}=k_{\text {dest }}$. An example fit is shown in Figure $2 \mathrm{~b}$ for ${ }^{13} \mathrm{CH}_{3} \mathrm{OH}$ and $\mathrm{O}_{3}$ growth curves during the irradiation of a ${ }^{13} \mathrm{CH}_{4}:{ }^{16} \mathrm{O}_{2}$ ice mixture (Experiment 3 ). The fits are very good, indicating that this model is indeed appropriate and that no additional parameters are required to describe the kinetics. Growth curves along with best-fit kinetic models for all other experiments are shown in Appendix B.

\section{RESULTS}

\subsection{Proof of concept: $\mathrm{CH}_{3} \mathrm{OH}$ production}

During irradiation of ${ }^{13} \mathrm{CH}_{4}:{ }^{16} \mathrm{O}_{2}$ mixtures, ${ }^{13} \mathrm{CH}_{3} \mathrm{OH}$ formation is observed in situ by the growth of the infrared band at $1008 \mathrm{~cm}^{-1}$. Figure $3 \mathrm{a}$ shows this feature in the spectrum of pure ${ }^{13} \mathrm{CH}_{3} \mathrm{OH}$. The band is not formed during irradiation of pure ${ }^{13} \mathrm{CH}_{4}$ or pure ${ }^{16} \mathrm{O}_{2}$, but does grow during irradiation of a mixture of ${ }^{13} \mathrm{CH}_{4}:{ }^{16} \mathrm{O}_{2}$. The growth of ${ }^{16} \mathrm{O}_{3}$ can also be seen in the pure ${ }^{16} \mathrm{O}_{2}$ and mixed ${ }^{13} \mathrm{CH}_{4}:{ }^{16} \mathrm{O}_{2}$ experiments.

Figure $3 \mathrm{~b}$ and $\mathrm{c}$ show results from the TPD following sample irradiation. In Figure $3 \mathrm{~b}$, the QMS trace for $m / z 33$, which corresponds to the mass of ${ }^{13} \mathrm{CH}_{3} \mathrm{OH}$, is observed for the mixed irradiated sample. Desorption occurs around $140 \mathrm{~K}$, as in the ${ }^{13} \mathrm{CH}_{3} \mathrm{OH}$ standard. No $\mathrm{m} / \mathrm{z} 33$ signal is observed for either of the pure control experiments. Figure $3 \mathrm{c}$ shows the integrated IR band area around $1008 \mathrm{~cm}^{-1}$ during the temperature ramp. Again, in the mixed irradiated experiment, the band disappears around $140 \mathrm{~K}$ and matches well with the ${ }^{13} \mathrm{CH}_{3} \mathrm{OH}$ standard.

Mixtures of $\mathrm{CD}_{4}:{ }^{18} \mathrm{O}_{2}$ similarly demonstrated growth of $\mathrm{CD}_{3}^{18} \mathrm{OD}$. A standard was not commercially available, however we identify the band at $952 \mathrm{~cm}^{-1}$ as $\mathrm{CD}_{3}^{18} \mathrm{OD}$ based on its similar growth to ${ }^{13} \mathrm{CH}_{3} \mathrm{OH}$ during irradiation (Figure 3d). Furthermore, $\mathrm{m} / z 38$ corresponding to $\mathrm{CD}_{3}^{18} \mathrm{OD}$ desorbs around $140 \mathrm{~K}$ coincident with the depletion of the IR band at $952 \mathrm{~cm}^{-1}$ (Figure $3 \mathrm{e}$ and $\mathrm{f}$ ). We therefore confirm the $\mathrm{O}$ insertion behavior in two isotopologue systems; based on these different lines of evidence, $\mathrm{CH}_{3} \mathrm{OH}$ is produced during the irradiation of $\mathrm{CH}_{4}: \mathrm{O}_{2}$ mixtures.

Table 3. $\mathrm{CH}_{3} \mathrm{OH}$ growth curve parameter fits: $\mathrm{CH}_{4}: \mathrm{O}_{2}$ experiments

\begin{tabular}{llc}
\hline \hline Expt. & $\mathrm{N}_{\mathrm{ss}}(\mathrm{ML})$ & $k_{r}\left(\mathrm{~s}^{-1}\right)$ \\
\hline 1 & $3.5[0.4]$ & $1.1[0.1] \times 10^{-4}$ \\
2 & $3.0[0.5]$ & $1.0[0.2] \times 10^{-4}$ \\
3 & $4.9[1.0]$ & $6.3[1.3] \times 10^{-5}$ \\
4 & $3.1[0.3]$ & $1.2[0.2] \times 10^{-4}$ \\
5 & $3.8[0.7]$ & $8.0[1.5] \times 10^{-5}$ \\
6 & $7.1[1.8]$ & $4.0[1.1] \times 10^{-5}$ \\
7 & $1.5[0.4]$ & $1.2[0.3] \times 10^{-4}$ \\
8 & $0.8[0.4]$ & $1.5[0.4] \times 10^{-4}$ \\
9 & $1.1[0.5]$ & $1.1[0.4] \times 10^{-4}$ \\
10 & $2.5[0.6]$ & $7.5[1.7] \times 10^{-5}$ \\
11 & $1.2[0.2]$ & $1.4[0.3] \times 10^{-4}$ \\
12 & $1.0[0.3]$ & $1.6[0.3] \times 10^{-4}$ \\
13 & $2.1[0.2]$ & $1.5[0.2] \times 10^{-4}$ \\
14 & $3.8[1.3]$ & $9.5[3.4] \times 10^{-5}$ \\
15 & $2.8[0.9]$ & $1.2[0.4] \times 10^{-4}$ \\
& & \\
\hline
\end{tabular}

Table 3 continued 

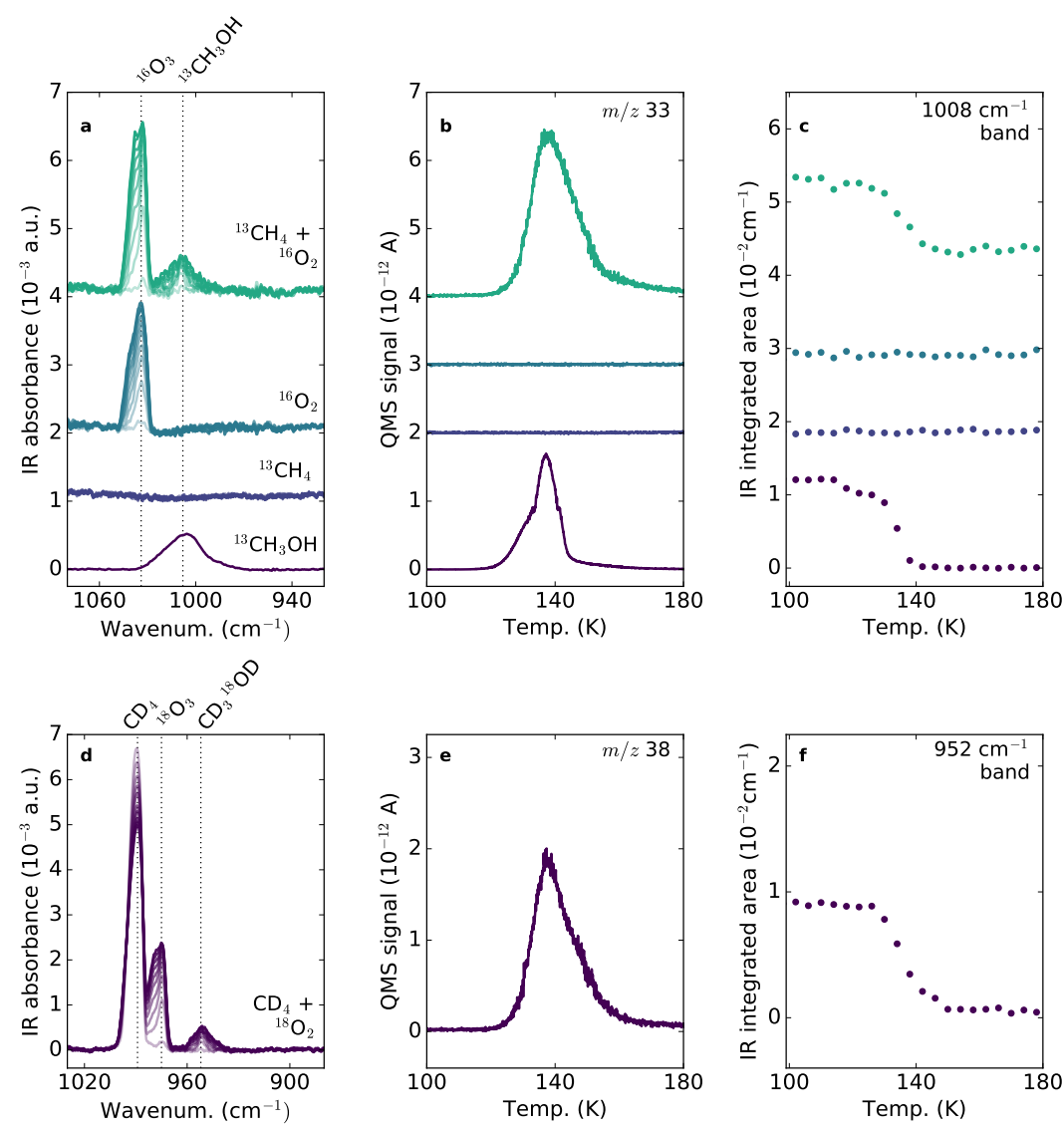

Figure 3. $\mathrm{CH}_{3} \mathrm{OH}$ production demonstrated through growth of IR features during irradiation (a,d), QMS traces during TPD (b,e), and integrated IR bands during TPD (c,f). Top panels show results for irradiated ${ }^{13} \mathrm{CH}_{4}+{ }^{16} \mathrm{O}_{2}$ mixture, irradiated ${ }^{16} \mathrm{O}_{2}$ only, irradiated ${ }^{13} \mathrm{CH}_{4}$ only, and a ${ }^{13} \mathrm{CH}_{3} \mathrm{OH}$ standard. Bottom panels show results for irradiated $\mathrm{CD}_{4}:{ }^{18} \mathrm{O}_{2}$.

Table 3 (continued)

\begin{tabular}{llc}
\hline \hline Expt. & $\mathrm{N}_{\mathrm{ss}}(\mathrm{ML})$ & $k_{r}\left(\mathrm{~s}^{-1}\right)$ \\
\hline 16 & $3.1[1.5]$ & $7.1[3.3] \times 10^{-5}$ \\
17 & $7.0[3.3]$ & $3.9[2.1] \times 10^{-5}$ \\
18 & $5.7[2.5]$ & $5.4[2.4] \times 10^{-5}$ \\
\hline
\end{tabular}

Uncertainties listed in brackets

\section{2. $\mathrm{O}_{2}: \mathrm{CH}_{4}$ Experiments}

\subsubsection{Rate constants}

To assess the energetics of oxygen insertion into $\mathrm{CH}_{4}$, experiments were performed at $9 \mathrm{~K}, 14 \mathrm{~K}, 19 \mathrm{~K}, 24 \mathrm{~K}$, and 25K. As described in Section 3.3, first-order kinetic models with photodissociative loss were used to fit each growth curve. Fits are typically performed for 2 hours of irradiation, however for ices thicker than 30ML fits are performed for 1 hour irradiations since peak overlap between the $\mathrm{CH}_{3} \mathrm{OH}$ and $\mathrm{O}_{3}$ feature becomes more severe for the higher product column densities. The parameters $k_{r}$ and $\mathrm{N}_{\mathrm{ss}}$ for each model are listed in Table 3.
The scatter in rate constants from all ${ }^{13} \mathrm{CH}_{4}:{ }^{16} \mathrm{O}_{2}$ experiments performed at $9 \mathrm{~K}$ was used to estimate uncertainties due to day-to-day systematics. We find a standard deviation of $\sim 20 \%$ in the rate constant values; for all experiments, this systematics uncertainty was added in quadrature with the growth curve fit errors in order to obtain the final uncertainties on $k_{r}$.

Figure 4 shows Arrhenius plots of the rate constants for different groups of experiments. For all ${ }^{13} \mathrm{CH}_{4}:{ }^{16} \mathrm{O}_{2}$ experiments at temperatures below $25 \mathrm{~K}$, there is no temperature dependence to the $\mathrm{CH}_{3} \mathrm{OH}$ formation rate constant: regardless of the ice thickness, the $\mathrm{CH}_{4}: \mathrm{O}_{2}$ ratio, or the presence of an inert capping gas, the value of $k_{r}$ is consistent around $10^{-4} \mathrm{~s}^{-1}$. The lower rate at $25 \mathrm{~K}$ is likely due to the onset of oxygen desorption. In experiments of $\mathrm{CD}_{4}:{ }^{18} \mathrm{O}_{2}$ the actual rate constants for $\mathrm{CD}_{3}^{18} \mathrm{OD}$ production are slightly lower than for ${ }^{13} \mathrm{CH}_{3} \mathrm{OH}$; this could be due to deuterium exchange altering the apparent kinetics, or a difference in zero-point energy impacting the reaction rates. As for ${ }^{13} \mathrm{CH}_{4}:{ }^{16} \mathrm{O}_{2}$ experiments there is no temperature dependence between $9 \mathrm{~K}$ and $19 \mathrm{~K}$, indicating similar underlying energetics for the different isotopologue systems. The lack 


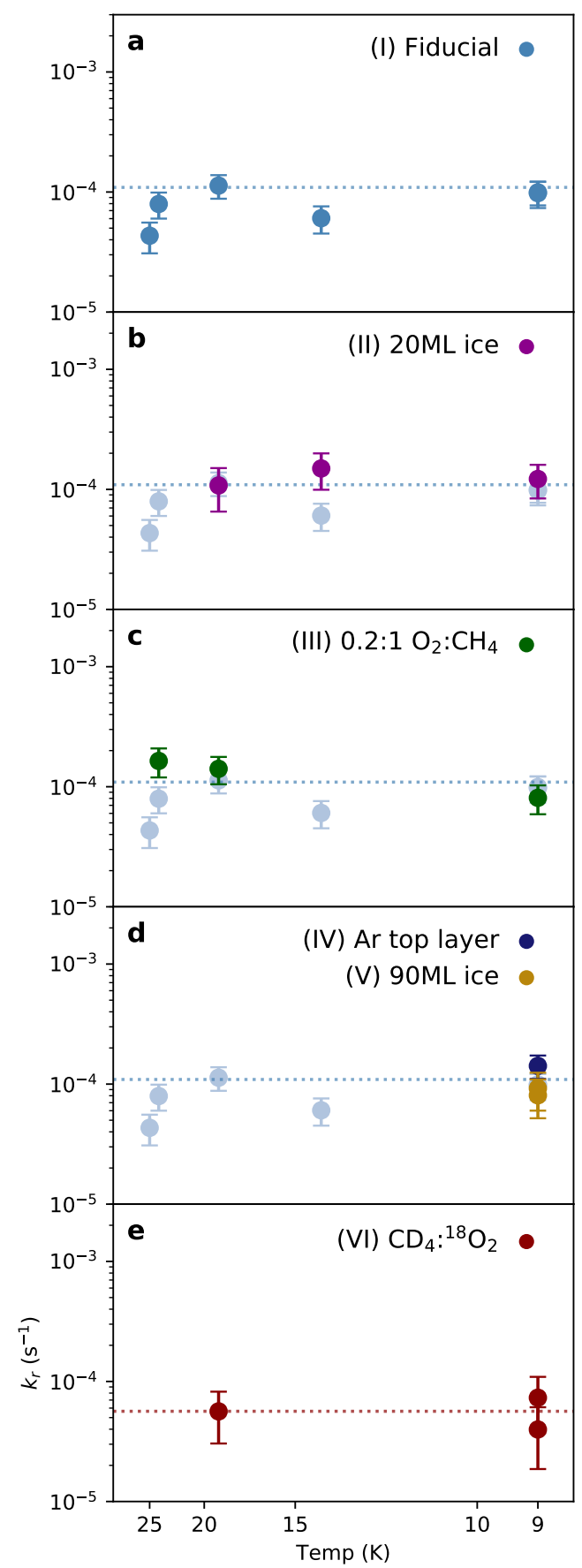

Figure 4. Arrhenius plots for $\mathrm{CH}_{3} \mathrm{OH}$ growth. Fiducial experiments $\left(\sim 1.4: 1{ }^{13} \mathrm{CH}_{4}:{ }^{16} \mathrm{O}_{2}, 50 \mathrm{ML}\right.$ total ice thickness) are shown in the top panel and reproduced in the other ${ }^{13} \mathrm{CH}_{4}:{ }^{16} \mathrm{O}_{2}$ experiments. All other panels show experiments that differ from the fiducial group as indicated, with experimental group number shown in parentheses. Dotted blue lines (a-d) show the mean rate constant for all ${ }^{13} \mathrm{CH}_{4}:{ }^{16} \mathrm{O}_{2}$ experiments; the dotted red line (e) shows the mean rate constant for $\mathrm{CD}_{4}:{ }^{18} \mathrm{O}_{2}$ experiments . of temperature dependence on the reaction rate is consistent with expectations from gas-phase and theoretical studies, which demonstrate barrierless or almost barrierless insertion of $\mathrm{O}\left({ }^{1} \mathrm{D}\right)$ into $\mathrm{CH}_{4}$. 


\subsubsection{Other products}

$\mathrm{O}_{3}, \mathrm{H}_{2} \mathrm{CO}, \mathrm{CO}, \mathrm{CO}_{2}$, and $\mathrm{H}_{2} \mathrm{O}$ are formed during the irradiation in addition to $\mathrm{CH}_{3} \mathrm{OH}$. These are identi- fied from their infrared features (Figure 5), which shift as predicted for different isotope combinations. IR line centers used for identification and corresponding references are listed in Table 4.

Table 4. Observed infrared line centers for isotopologue experiments

\begin{tabular}{llcllc}
\hline \hline Position $\left(\mathrm{cm}^{-1}\right)$ & Assignment & Reference & Position $\left(\mathrm{cm}^{-1}\right)$ & Assignment & Reference \\
\hline$\frac{13 \mathrm{CH}_{4}+{ }^{16} \mathrm{O}_{2}}{3000}$ & & & $\frac{13 \mathrm{CH}_{4}+{ }^{18} \mathrm{O}_{2}}{3}$ & & \\
2825 & ${ }^{13} \mathrm{CH}_{4}$ & $\mathrm{a}$ & 3000 & ${ }^{13} \mathrm{CH}_{4}$ & $\mathrm{a}$ \\
2807 & ${ }^{13} \mathrm{CH}_{3} \mathrm{OH}$ & $\mathrm{a}$ & 2807 & ${ }^{13} \mathrm{CH}_{4}$ & $\mathrm{a}$ \\
2276 & ${ }^{13} \mathrm{CH}_{4}$ & $\mathrm{a}$ & 2240 & ${ }^{13} \mathrm{C}^{18} \mathrm{O}_{2}$ & $\mathrm{e}$ \\
2092 & ${ }^{13} \mathrm{CO}_{2}$ & $\mathrm{~b}$ & 2039 & ${ }^{13} \mathrm{C}^{18} \mathrm{O}$ & $\mathrm{f}$ \\
1683 & ${ }^{13} \mathrm{CO}$ & $\mathrm{b}$ & 1652 & $\mathrm{H}_{2}^{13} \mathrm{C}^{18} \mathrm{O}$ & $\mathrm{g}$ \\
1652 & $\mathrm{H}_{2}^{13} \mathrm{CO}$ & $\mathrm{c}^{*}$ & 1645 & $\mathrm{H}_{2}^{18} \mathrm{O}$ & $\mathrm{h}$ \\
1498 & $\mathrm{H}_{2} \mathrm{O}$ & $\mathrm{b}$ & 1291 & ${ }^{13} \mathrm{CH}_{4}$ & $\mathrm{a}$ \\
1291 & $\mathrm{H}_{2}^{13} \mathrm{CO}$ & $\mathrm{c}^{*}$ & 979 & ${ }^{18} \mathrm{O}_{3}$ & $\mathrm{~d}$ \\
1034 & ${ }^{13} \mathrm{CH}$ & $\mathrm{a}$ & & ${ }^{13} \mathrm{CH}_{3}^{18} \mathrm{OH}$ & $\mathrm{g}$ \\
1008 & $\mathrm{O}_{3}$ & $\mathrm{~d}$ & $12 \mathrm{CH}+{ }^{*} \mathrm{O}_{2}$ & & \\
$\frac{12}{C D_{4}+{ }^{18} \mathrm{O}_{2}}$ & ${ }^{13} \mathrm{CH}_{3} \mathrm{OH}$ & $\mathrm{a}$ & 3009 & $\mathrm{CH}_{4}$ & $\mathrm{a}$ \\
3237 & & & 2822 & $\mathrm{H}_{2} \mathrm{CO}$ & $\mathrm{b}$ \\
2306 & $\mathrm{CD}_{4}$ & $\mathrm{a}$ & 2815 & $\mathrm{CH}_{4}$ & $\mathrm{a}$ \\
2251 & $\mathrm{C}^{18} \mathrm{O}_{2}$ & $\mathrm{e}$ & 2341 & $\mathrm{CO}_{2}$ & $\mathrm{~b}$ \\
2088 & $\mathrm{CD}_{4}$ & $\mathrm{a}$ & 2139 & $\mathrm{CO}$ & $\mathrm{b}$ \\
1631 & $\mathrm{C}^{18} \mathrm{O}$ & $\mathrm{f}$ & 1718 & $\mathrm{H}_{2} \mathrm{CO}$ & $\mathrm{b}$ \\
989 & $\mathrm{D}_{2} \mathrm{C}^{18} \mathrm{O}$ & $\mathrm{g}$ & 1659 & $\mathrm{H}_{2} \mathrm{O}$ & $\mathrm{b}$ \\
975 & $\mathrm{CD}_{4}$ & $\mathrm{a}$ & 1495 & $\mathrm{H}_{2} \mathrm{CO}$ & $\mathrm{b}$ \\
952 & $\mathrm{O}_{3}$ & $\mathrm{~d}$ & 1300 & $\mathrm{CH}_{4}$ & $\mathrm{a}$ \\
& $\mathrm{CD}_{3}^{18} \mathrm{OD}$ & $\mathrm{g}$ & 1033 & $\mathrm{O}_{3}$ & $\mathrm{~d}$ \\
\hline & & & & $\mathrm{CH}_{3} \mathrm{OH}$ & $\mathrm{b}$ \\
\hline
\end{tabular}

\footnotetext{
* Original assignment in RAIRS

${ }^{a}$ Reference spectrum in this work; ${ }^{b}$ Bouilloud et al. (2015); ${ }^{\mathrm{c}}$ Kaiser et al. (2015); ${ }^{\mathrm{d}}$ SchriverMazzuoli et al. (1995); ${ }^{\mathrm{e}} \mathrm{Du}$ et al. (2011); ${ }^{\mathrm{f}}$ Legay-Sommaire \& Legay (1982); ${ }^{\mathrm{g}}$ Assigned based on shifts from other isotopologues; ${ }^{h}$ Zheng et al. (2011)
}

None of the isotopologue combinations result in clean IR features for all products. For unblended features in the ${ }^{13} \mathrm{CH}_{4}:{ }^{16} \mathrm{O}_{2}$ experiments, growth curves can be measured from integrated IR spectra using the band strengths listed in Table 2. An example set of growth curves is shown in Figure $6 . \mathrm{CH}_{4}$ is steadily consumed over the course of the experiment; $\mathrm{CH}_{3} \mathrm{OH}$ and $\mathrm{H}_{2} \mathrm{CO}$ growth begins at early times, while $\mathrm{CO}_{2}$ growth accelerates later in the irradiation.

Final yields of all products are calculated from the IR spectrum after 2 hours of irradiation. For products with blended features, yields are estimated as follows. The $\mathrm{CO}$ band is blended in ${ }^{13} \mathrm{CH}_{4}:{ }^{16} \mathrm{O}_{2}$ experiments, but not for ${ }^{13} \mathrm{CH}_{4}:{ }^{18} \mathrm{O}_{2}$ and ${ }^{12} \mathrm{CH}_{4}:{ }^{16} \mathrm{O}_{2}$ (Exps. 19 and 20 ). In both unblended cases the ratio of $\mathrm{CO} / \mathrm{CO}_{2}$ is equal to $\sim 1.3$. Therefore, the $\mathrm{CO}$ yield in ${ }^{13} \mathrm{CH}_{4}:{ }^{16} \mathrm{O}_{2}$ experiments is estimated by multiplying the $\mathrm{CO}_{2}$ yield by 1.3 . $\mathrm{H}_{2} \mathrm{O}$ overlaps with the $\mathrm{H}_{2} \mathrm{CO}$ feature at $1683 \mathrm{~cm}^{-1}$. To estimate the $\mathrm{H}_{2} \mathrm{O}$ yield, the $\mathrm{H}_{2} \mathrm{CO}$ contribution is calculated based on the area of its $1498 \mathrm{~cm}^{-1}$ feature and then subtracted from the integrated area of the entire blended feature. 


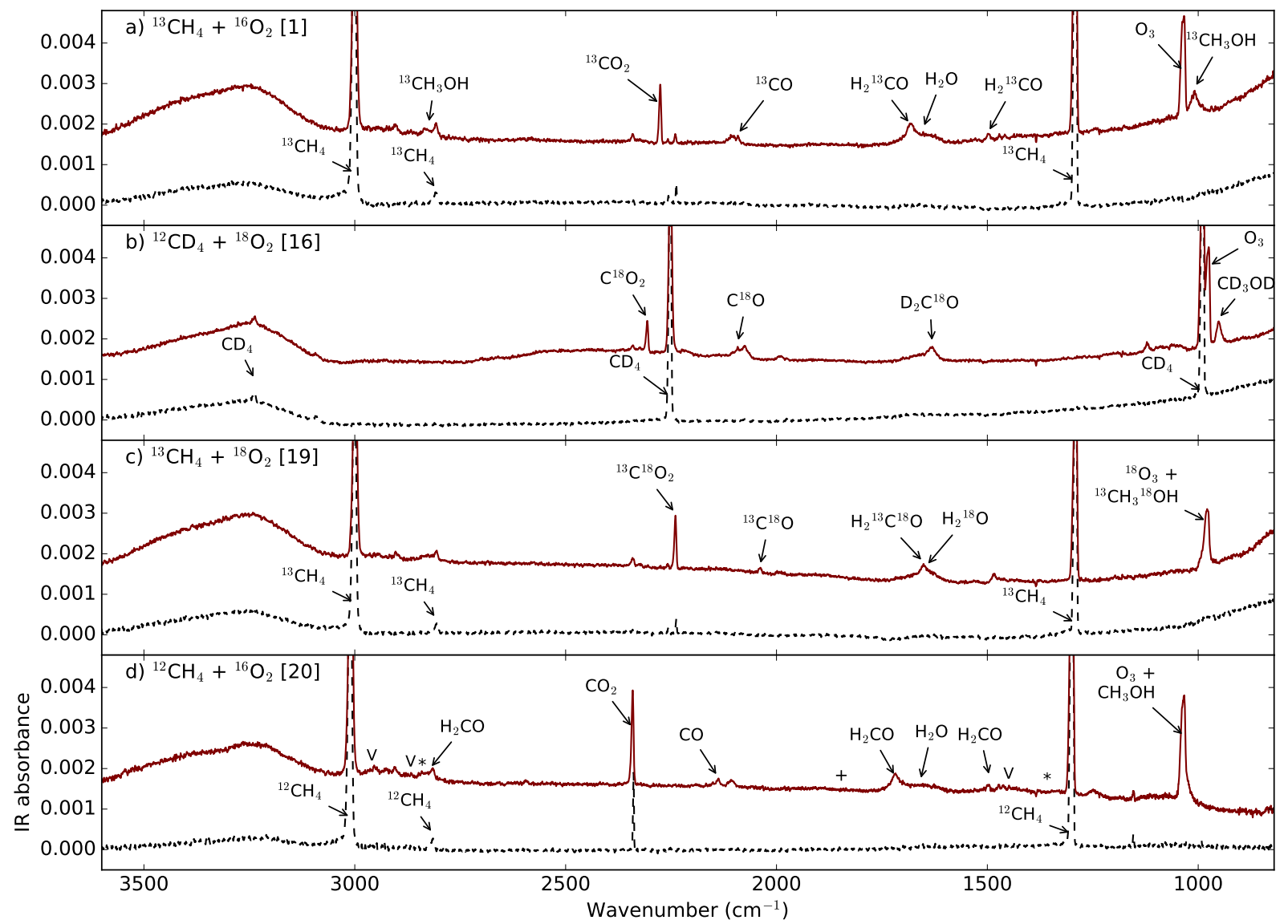

Figure 5. $\mathrm{CH}_{4}+\mathrm{O}_{2}$ ice mixtures before (black dashed line) and after (red solid line) $2 \mathrm{~h}$ UV irradiation, with reactant and product IR peaks labeled. Each panel shows a different isotope combination, with the experiment number indicated in brackets. In the ${ }^{12} \mathrm{CH}_{4}:{ }^{16} \mathrm{O}_{2}$ experiment (d), line centers for $\mathrm{H}_{2} \mathrm{O}_{2}, \mathrm{C}_{2} \mathrm{H}_{6}$, and $\mathrm{HCO}$ are shown with *'s, V's, and +'s respectively.

Table 5. Average product yields after $2 \mathrm{~h}$ irradiation

\begin{tabular}{cccccc}
\hline \hline $\mathrm{CO}$ & $\begin{array}{c}\mathrm{CO}_{2} \\
\left(\% \text { wrt } \mathrm{CH}_{4} \text { consumed }\right)\end{array}$ & $\mathrm{H}_{2} \mathrm{CO}$ & $\mathrm{CH}_{3} \mathrm{OH}$ & $\begin{array}{l}\mathrm{H}_{2} \mathrm{O} \\
\left(\% \text { wrt } \mathrm{O}_{2} \text { dose }\right)\end{array}$ \\
\hline $6.8[0.6]$ & $5.3[0.5]$ & $26.3[8.7]$ & $60.0[6.2]$ & $11.8[4.5]$ & $12.7[1.4]$ \\
\hline
\end{tabular}

Standard deviations listed in brackets

Average product yields (Table 5) are calculated from experiments in Groups I, IV, and V, which all have sufficiently large IR features for all molecules to be quantified. Total yields of carbon-bearing products are consistent with the measured consumption of $\mathrm{CH}_{4}$ when considering band strength uncertainties.

\subsubsection{Branching ratio}

The ratios of carbon-bearing products can be used to derive the branching ratio of $\mathrm{O}\left({ }^{1} \mathrm{D}\right)+\mathrm{CH}_{4} \rightarrow \mathrm{CH}_{3} \mathrm{OH}$. As seen in Table $5, \mathrm{CH}_{3} \mathrm{OH}$ has an average yield of $60 \pm 6 \%$ with respect to $\mathrm{CH}_{4}$ consumption. This represents a lower limit to the $\mathrm{CH}_{3} \mathrm{OH}$ formation efficiency since, as described in Section 3.4, $\mathrm{CH}_{3} \mathrm{OH}$ is also susceptible to photodissociation. We can calculate the maximum abundance of carbon-bearing derivatives that may be formed from $\mathrm{CH}_{3} \mathrm{OH}$ photoprocessing using the integrated rate law for product formation by Reaction 7 :

$$
[\operatorname{pr}](t)=\frac{\mathrm{N}_{\mathrm{ss}}\left[k_{\text {dest }}\left(1-e^{-k_{r} t}\right)-k_{r}\left(1-e^{-k_{\text {dest }} t}\right)\right]}{k_{\text {dest }}-k_{r}},
$$

where $[\mathrm{pr}]$ represents the combined abundance of products from $\mathrm{CH}_{3} \mathrm{OH}$ destruction. This represents an upper limit on the actual amount of products formed since not every photon absorption is necessarily dissociative. Us- 

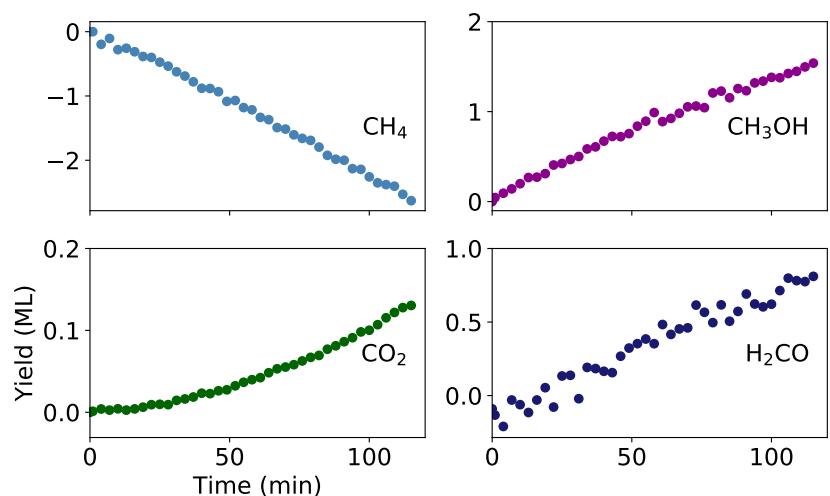

Figure 6. Growth curves in a ${ }^{13} \mathrm{CH}_{4}:{ }^{16} \mathrm{O}_{2}$ experiment (Exp. 3) for molecules with unblended IR features: $\mathrm{CH}_{4}\left(\nu_{4}\right.$ bend), $\mathrm{CH}_{3} \mathrm{OH}\left(\nu_{8} \mathrm{CO}\right.$ str $), \mathrm{CO}_{2}\left(\nu_{3}\right.$ a-str $)$, and $\mathrm{H}_{2} \mathrm{CO}\left(\nu_{3} \mathrm{CH}_{2} \mathrm{sc}\right)$.

ing the values of $k_{r}$ and $\mathrm{N}_{\mathrm{ss}}$ derived from fitting $\mathrm{CH}_{3} \mathrm{OH}$ growth curves (Table 3), we find an average upper limit of $9.7 \pm 1 \%$ photo-products with respect to $\mathrm{CH}_{4}$ consumption after 2 hours.

Assuming that $\mathrm{CO}$ and $\mathrm{CO}_{2}$ are daughter species of $\mathrm{H}_{2} \mathrm{CO}$ processing, the summed abundance of $\mathrm{CO}$, $\mathrm{CO}_{2}$, and $\mathrm{H}_{2} \mathrm{CO}$ represents the total number of $\mathrm{H}_{2} \mathrm{CO}$ molecules that are formed over the course of an experiment. Experimentally, the average total abundance of $\mathrm{H}_{2} \mathrm{CO}+\mathrm{CO}+\mathrm{CO}_{2}$ is equal to $38 \pm 9 \%$ with respect to $\mathrm{CH}_{4}$ consumption. Therefore, we observe more carbonbearing side products than can be produced purely through $\mathrm{CH}_{3} \mathrm{OH}$ photoprocessing. The remaining products are likely formed from the product channel $\mathrm{O}\left({ }^{1} \mathrm{D}\right)$ $+\mathrm{CH}_{4} \rightarrow \mathrm{H}_{2} \mathrm{CO}+\mathrm{H}_{2}$. The branching ratio of this channel should be equal to the difference between the observed side products and calculated abundances of photo-products. This value will represent a lower limit since the calculated photoproduct yield is based on the assumption that every photon absorbed by $\mathrm{CH}_{3} \mathrm{OH}$ is dissociative. We obtain a lower limit for the $\mathrm{H}_{2} \mathrm{CO}$ channel branching ratio of $29 \pm 9 \%$. Based on this analysis we can therefore bracket the branching ratio of the $\mathrm{CH}_{3} \mathrm{OH}$ channel between $\sim 60-71 \%$, with the lower limit representing a scenario with no $\mathrm{CH}_{3} \mathrm{OH}$ photodissociation and the upper limit representing the maximum possible $\mathrm{CH}_{3} \mathrm{OH}$ photodissociation.

Performing this same treatment at other time points, we find that the mean $\mathrm{H}_{2} \mathrm{CO}$ branching ratio begins small and increases over the irradiation, flattening out to $28-29 \%$ after 90 minutes. This is consistent with a scenario in which some $\mathrm{H}_{2} \mathrm{CO}$ comes directly from $\mathrm{O}$ insertion, and some from $\mathrm{CH}_{3} \mathrm{OH}$ dissociation.

We note that an abstraction pathway of $\mathrm{O}+\mathrm{CH}_{4}$ $\rightarrow \mathrm{OH}+\mathrm{CH}_{3}$ is a negligible or non-existent channel: if important, there should be considerable amounts of $\mathrm{C}_{2} \mathrm{H}_{6}$ and $\mathrm{H}_{2} \mathrm{O}_{2}$ from $\mathrm{CH}_{3}+\mathrm{CH}_{3}$ and $\mathrm{OH}+\mathrm{OH}$, and we do not detect $\mathrm{C}_{2} \mathrm{H}_{6}$ or $\mathrm{H}_{2} \mathrm{O}_{2}$ as products. We deter- mine upper limits for each species using Experiment 20 $\left({ }^{12} \mathrm{CH}_{4}:{ }^{16} \mathrm{O}_{2}\right)$, as band strengths and positions are most reliable for the standard isotopes. The line centers where $\mathrm{H}_{2} \mathrm{O}_{2}$ and $\mathrm{C}_{2} \mathrm{H}_{6}$ should appear are shown in Figure 5d; qualitatively, it is clear that these are minor species if they are present at all. To determine the $\mathrm{C}_{2} \mathrm{H}_{6}$ upper limit, we use the $\nu_{10}$ band at $2972 \mathrm{~cm}^{-1}\left(2.2 \times 10^{-17} \mathrm{~cm}\right.$ molec $^{-1}$; Hudson et al. 2014). We find an upper limit of $0.05 \mathrm{ML}$, or $\sim 1.7 \%$ with respect to $\mathrm{CH}_{4}$ consumption. Only RAIRS band strengths are available in the literature for $\mathrm{H}_{2} \mathrm{O}_{2}$ and so, as for described for $\mathrm{O}_{3}$ in Section 3.3, we scale the RAIRS band strength reported in Loeffler et al. (2006). For the $\nu_{6}$ bending mode at $1368 \mathrm{~cm}^{-1}$ this yields a band strength of $3.0 \times 10^{-17} \mathrm{~cm} \mathrm{molec}^{-1}$. We find an $\mathrm{H}_{2} \mathrm{O}_{2}$ upper limit of 0.01ML, compared to a typical $\mathrm{O}_{3}$ yield of $\sim 4 \mathrm{ML}$ for experiments with similar initial doses. Thus, these species are either not produced or are a small fraction of the total reaction.

\subsection{CO dilution experiments}

In order to evaluate whether $\mathrm{CH}_{3} \mathrm{OH}$ formation via $\mathrm{O}\left({ }^{1} \mathrm{D}\right)$ insertion into $\mathrm{CH}_{4}$ is also efficient in a more astrophysically realistic environment, we performed a set of experiments (21-26) in which the reactants ${ }^{16} \mathrm{O}_{2}$ and ${ }^{13} \mathrm{CH}_{4}$ were diluted in ${ }^{12} \mathrm{CO}$. CO absorbs UV radiation, thereby introducing the possibility of contamination from CO-induced chemistry. However, by following the formation of ${ }^{12} \mathrm{C}$ vs. ${ }^{13} \mathrm{C}$ products we determine that ${ }^{12} \mathrm{CO}$ mainly reacts to form ${ }^{12} \mathrm{CO}_{2}$. We follow the growth of ${ }^{13} \mathrm{CH}_{3} \mathrm{OH}$ in order to determine the oxygen insertion kinetics.

Table 6. $\mathrm{CH}_{3} \mathrm{OH}$ growth curve parameter fits: $\mathrm{CO}: \mathrm{O}_{2}: \mathrm{CH}_{4}$ experiments

\begin{tabular}{lcc}
\hline \hline Expt. & $\mathrm{N}_{\mathrm{ss}}(\mathrm{ML})$ & $k_{r}\left(\mathrm{~s}^{-1}\right)$ \\
\hline 21 & $0.54[0.15]$ & $1.1[0.3] \times 10^{-4}$ \\
22 & $0.70[0.33]$ & $5.1[2.6] \times 10^{-5}$ \\
23 & $0.38[0.15]$ & $9.8[3.9] \times 10^{-5}$ \\
24 & $1.43[0.90]$ & $1.6[1.3] \times 10^{-5}$ \\
25 & $0.54[0.45]$ & $3.7[3.1] \times 10^{-5}$ \\
26 & $0.55[0.46]$ & $3.5[3.1] \times 10^{-5}$ \\
\hline
\end{tabular}

Uncertainties listed in brackets

Rate constants for $\mathrm{CH}_{3} \mathrm{OH}$ formation are determined by fitting Equation 8 as before. $\mathrm{CH}_{3} \mathrm{OH}$ formation rate constants are derived at temperatures between 9K-19K for ices of two different compositions: 4:1:1 ${ }^{12} \mathrm{CO}:{ }^{16} \mathrm{O}_{2}:{ }^{13} \mathrm{CH}_{4}$ mixtures and 7:1:1 ${ }^{12} \mathrm{CO}:{ }^{16} \mathrm{O}_{2}:{ }^{13} \mathrm{CH}_{4}$ mixtures. Since product yields are reduced when the reactants are diluted in $\mathrm{CO}$, uncertainties on the rate 


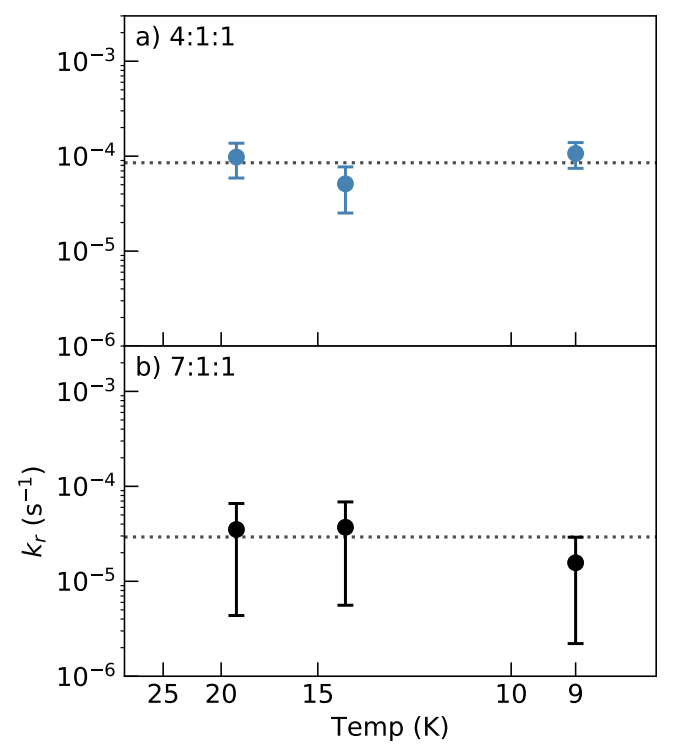

Figure 7. Rate constants as a function of temperature for $\mathrm{CO}$ dilution experiments. a) $4: 1: 1{ }^{12} \mathrm{CO}:{ }^{16} \mathrm{O}_{2}:{ }^{13} \mathrm{CH}_{4}$. b) $7: 1: 1{ }^{12} \mathrm{CO}:{ }^{16} \mathrm{O}_{2}:{ }^{13} \mathrm{CH}_{4}$.

constants are higher than in the $\mathrm{O}_{2}: \mathrm{CH}_{4}$ experiments. Still, as can be seen from the Arrhenius plots (Figure 7), there is no temperature dependence to the $\mathrm{CH}_{3} \mathrm{OH}$ formation rate. The parameters $k_{r}$ and $\mathrm{N}_{s s}$ are shown in Table 6.

\section{DISCUSSION}

\subsection{Reaction network}

As mentioned in Section 1, for the UV wavelengths in this study, $\mathrm{O}_{2}$ dissociation proceeds through the channel $\mathrm{O}_{2} \rightarrow \mathrm{O}\left({ }^{1} \mathrm{D}\right)+\mathrm{O}\left({ }^{3} \mathrm{P}\right)$ with an efficiency of unity (Lee et al. 1977). Thus, our ices should contain equal parts $\mathrm{O}\left({ }^{1} \mathrm{D}\right)$ and $\mathrm{O}\left({ }^{3} \mathrm{P}\right)$. We now draw from gas-phase, theoretical, and, when available, condensed-phase studies to interpret the formation pathways of our observed products. Figure 8 presents a summary of the possible pathways we discuss.

$\mathrm{CH}_{3} \mathrm{OH}$ formation: In the gas phase the insertion of $\mathrm{O}\left({ }^{1} \mathrm{D}\right)$ into $\mathrm{CH}_{4}$ results in an excited $\mathrm{CH}_{3} \mathrm{OH}$ product, which undergoes unimolecular dissociation to form mainly $\mathrm{OH}+\mathrm{CH}_{3}$ unless it is stabilized by e.g. collision (DeMore \& Raper 1967; Parnis et al. 1993) or supersonic expansion (Hays et al. 2015). As our experiments involve condensed ices, it is fully consistent that the intact $\mathrm{CH}_{3} \mathrm{OH}$ molecule is observed due to energy dissipation into the solid. This insertion process has been demonstrated to have essentially no barrier in gas-phase and theoretical studies (DeMore \& Raper 1967; Yu \& Muckerman 2004), which is again consistent with the lack of a temperature dependence to $\mathrm{CH}_{3} \mathrm{OH}$ formation in our experiments.

In contrast, ground state $\mathrm{O}\left({ }^{3} \mathrm{P}\right)$ oxygen atoms follow an abstraction channel with $\mathrm{CH}_{4}$ to produce $\mathrm{OH}+\mathrm{CH}_{3}$, with an estimated barrier of over 5000K (e.g. Walch \& Dunning Jr. 1980; Zhao et al. 2016). Such an abstraction channel could conceivably lead to $\mathrm{CH}_{3} \mathrm{OH}$ production through radical recombination, however this is unlikely due to the high theoretical energy barrier. Furthermore, as stated in Section 4.2.3, the upper limits for $\mathrm{C}_{2} \mathrm{H}_{6}$ and $\mathrm{H}_{2} \mathrm{O}_{2}$ are on the order of a percent or less of the total consumed $\mathrm{CH}_{4}$, indicating that abstraction is not an important process in this system.

$\mathrm{O}_{3}$ formation: $\mathrm{O}_{3}$ formation from energetic processing of molecular oxygen under astrochemically relevant conditions has been well-described in the literature (e.g. Schriver-Mazzuoli et al. 1995; Bennett \& Kaiser 2005; Sivaraman et al. 2011). The mechanism for $\mathrm{O}_{3}$ formation under these conditions is $\mathrm{O}\left({ }^{3} \mathrm{P}\right)+\mathrm{O}_{2}$. This is likely the formation pathway occurring in our ices as well since $\mathrm{O}\left({ }^{3} \mathrm{P}\right)$ should be formed in similar quantities as $\mathrm{O}\left({ }^{1} \mathrm{D}\right)$, and the barrier to react with $\mathrm{CH}_{4}$, the other available reaction partner, is high.

$\mathrm{H}_{2} \mathrm{CO}$ formation: A fraction of $\mathrm{H}_{2} \mathrm{CO}$ may be formed from photo-processing of $\mathrm{CH}_{3} \mathrm{OH}$, as has been demonstrated in previous UV irradiation studies (e.g. Gerakines et al. 1996; Öberg et al. 2009). As discussed in Section 4.2.3, the majority of $\mathrm{H}_{2} \mathrm{CO}$ is likely formed directly from insertion of $\mathrm{O}\left({ }^{1} \mathrm{D}\right)$ into $\mathrm{CH}_{4}$. Indeed, following $\mathrm{CH}_{3} \mathrm{OH}, \mathrm{H}_{2} \mathrm{CO}$ is the next most stable possible product of $\mathrm{O}\left({ }^{1} \mathrm{D}\right.$ ) insertion into $\mathrm{CH}_{4}$ (Chang \& Lin 2002; Yu \& Muckerman 2004), and gas-phase and matrix studies typically show $\mathrm{H}_{2} \mathrm{CO}$ as the second-most common insertion product (e.g. DeMore \& Raper 1967; Appelman et al. 1989; Hays et al. 2015). Moreover, from Figure 6 the shape of the $\mathrm{H}_{2} \mathrm{CO}$ growth curve is different from the second-generation product $\mathrm{CO}_{2}$, but quite similar to that of the primary insertion product $\mathrm{CH}_{3} \mathrm{OH}$. This is consistent with a scenario in which the majority of $\mathrm{H}_{2} \mathrm{CO}$ forms from the same mechanism as $\mathrm{CH}_{3} \mathrm{OH}$, as opposed to growing only from $\mathrm{CH}_{3} \mathrm{OH}$ processing.

$C O$ formation: Successive $\mathrm{H}$ abstractions could form $\mathrm{CO}$ via $\mathrm{H}_{2} \mathrm{CO} \rightarrow \mathrm{HCO} \rightarrow \mathrm{CO}$, but as seen in Figure $5 \mathrm{~d}$ $\mathrm{HCO}$ is not observed in the IR despite having a comparable band strength to CO (Bennett et al. 2007). Alternatively, $\mathrm{CO}$ may be produced by unimolecular dissociation of $\mathrm{H}_{2} \mathrm{CO}$ to directly form $\mathrm{CO}+\mathrm{H}_{2}$, which is a demonstrated photo-process of $\mathrm{H}_{2} \mathrm{CO}$ in the condensed phase (Thomas Jr. \& Guillory 1973) and explains the lack of observed HCO.

$\mathrm{H}_{2} \mathrm{O}$ formation: Hydrogenation channels beginning with $\mathrm{O}, \mathrm{O}_{2}$, or $\mathrm{O}_{3}$ have been shown experimentally to lead to water formation (Dulieu et al. 2010; Ioppolo et al. 2008; Romanzin et al. 2011) and are likely at play in this system given the availability of these reactants. An alternative pathway is the formation and subsequent hydrogenation of $\mathrm{OH}$ by the abstraction pathway of $\mathrm{O}\left({ }^{3} \mathrm{P}\right)$ 


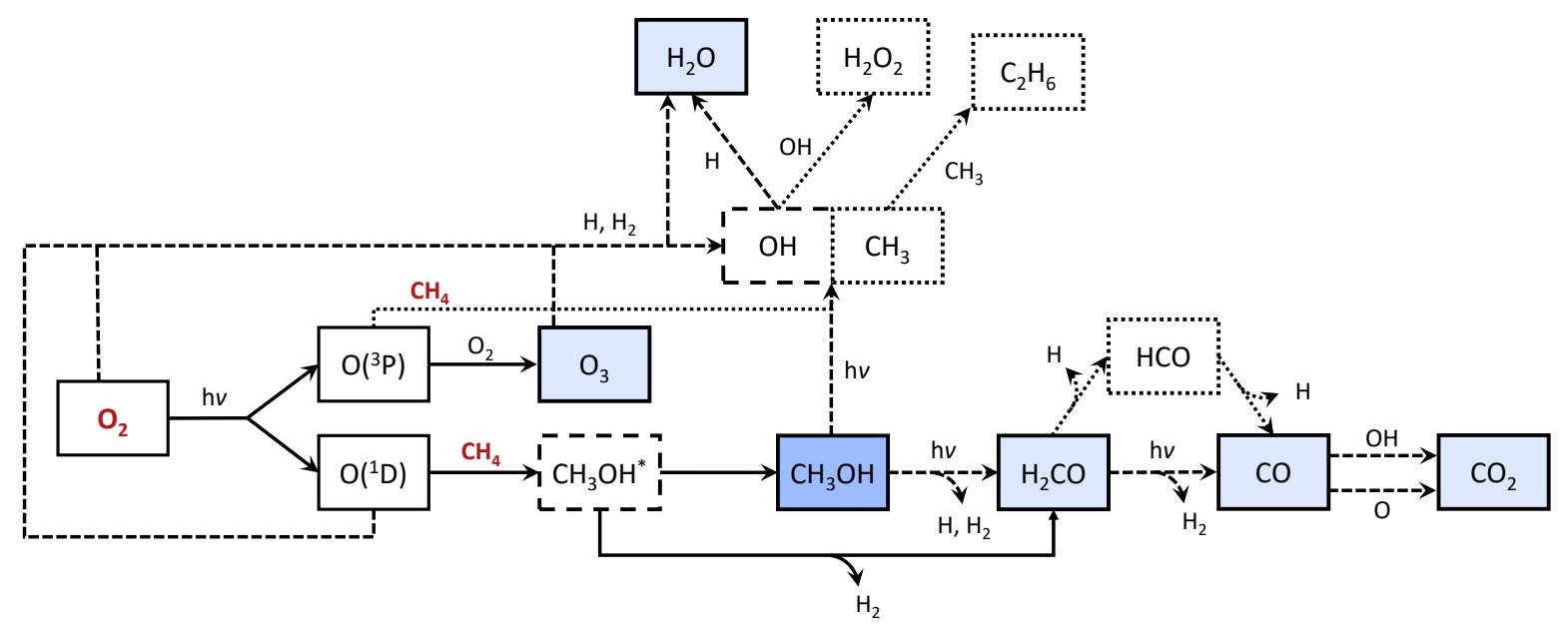

Figure 8. Proposed network for this reaction system. Reactants are shown with red text, and observed products as blue boxes. Boxes with dashed borders indicate intermediates that are likely based on observed products; dotted borders indicate intermediates/products that are not observed and therefore minor channels if present at all. Solid lines represent pathways leading to primary products; dashed lines represent pathways leading to secondary products; dotted lines represent pathways that are likely minor contributions based on the lack of observed products.

with $\mathrm{CH}_{4}$. However, given the high barrier to the $\mathrm{O}\left({ }^{3} \mathrm{P}\right)$ abstraction pathway and lack of observed $\mathrm{C}_{2} \mathrm{H}_{6}$, reaction pathways beginning with $\mathrm{O}, \mathrm{O}_{2}$, or $\mathrm{O}_{3}$ are more likely.

$\mathrm{CO}_{2}$ formation: From the shape of its growth curve (Figure 6), $\mathrm{CO}_{2}$ is almost certainly a second-generation product, with its abundance increasing at later times in the experiment. One possible route for $\mathrm{CO}_{2}$ formation is $\mathrm{CO}+\mathrm{OH}$, with $\mathrm{OH}$ formed as an intermediate along the $\mathrm{H}_{2} \mathrm{O}$ formation channels. Studies have also shown $\mathrm{CO}_{2}$ formation from CO + O (Parnis et al. 1993; Madzunkov et al. 2006; Minissale et al. 2013). It is unclear whether the higher energy barrier of the $\mathrm{CO}+\mathrm{O}$ pathway or the higher diffusion barrier of the $\mathrm{CO}+\mathrm{OH}$ pathway will dominate under these conditions.

\subsection{O insertion reaction}

We derive a branching ratio for the $\mathrm{CH}_{3} \mathrm{OH}$ channel of $\sim 65 \%$, with the remaining insertions leading to $\mathrm{H}_{2} \mathrm{CO}$ formation. Fragmentation does not appear to be an important process in this system as evidenced by the lack of $\mathrm{CH}_{3}$ and $\mathrm{OH}$ chemistry. Solid-state oxygen insertions should therefore lead to a net increase in chemical complexity, in most cases increasing the size of the product molecule and in all cases forming an O-containing organic from a hydrocarbon.

We observe no temperature dependence to $\mathrm{CH}_{3} \mathrm{OH}$ formation via oxygen insertion, consistent with gasphase and theoretical studies which show a negligible or non-existent energy barrier. With these experiments alone, however, we cannot definitively rule out the presence of a small energy barrier for several reasons. First, our experiments cannot isolate any contributions from tunneling, which may play a role at the low tempera- tures studied here. Additionally, it is possible that a diffusion barrier for $\mathrm{O}$ atoms could mask an insertion barrier, since the atoms would have to overcome a barrier to diffuse away than to react. Based on rather low diffusion barriers for $\mathrm{O}$ atoms in models ( $400 \mathrm{~K}$; Garrod \& Pauly 2011), only a small reaction barrier could be masked in this way. Finally, the photodissociation of $\mathrm{O}_{2}$ may lead to the formation of "hot" oxygen atoms: the threshold for formation of $\mathrm{O}\left({ }^{3} \mathrm{P}\right)+\mathrm{O}\left({ }^{1} \mathrm{D}\right)$ is $175 \mathrm{~nm}$ (Nee \& Lee 1997), whereas the UV lamp in this study peaks at $160.8 \mathrm{~nm}$. This energy difference represents $\sim 0.6 \mathrm{eV}$. Some of this excess energy will be dissipated into the solid, but it is possible that oxygen atoms formed as a result of photodissociation are superthermal.

A hot atom mechanism may also be at play in ISM ices: as described in Section 1 , the $\mathrm{O}\left({ }^{1} \mathrm{D}\right)$ required for oxygen insertion chemistry in astrophysical settings is likely formed from photolysis or radiolysis of oxygenbearing molecules. The possibility that oxygen insertion is driven by hot atoms in our experiments makes it important to explore in ices with more realistic compositions than $\mathrm{O}_{2}: \mathrm{CH}_{4}$ mixtures. In the $\mathrm{CO}$-dominated experiments (Section 4.3), we found that even when the reactants are diluted in a $\mathrm{CO}$ ice, the $\mathrm{CH}_{3} \mathrm{OH}$ formation rate follows the same temperature-independent trend as in the $\mathrm{O}_{2}: \mathrm{CH}_{4}$ only experiments. Thus, whether $\mathrm{O}\left({ }^{1} \mathrm{D}\right)$ insertion is mediated by a hot atom mechanism or not, we find that it can proceed at very low temperatures in a barrierless/pseudo-barrierless manner.

When taken along with the theoretical insertion barrier of just $\sim 280 \mathrm{~K}$ and a negligible measured insertion barrier in the gas phase, an essentially barrierless icephase insertion process is the most likely explanation 
for our experimental results. We conclude that insertion is a dominant reaction pathway when excited $\mathrm{O}\left({ }^{1} \mathrm{D}\right)$ is present, and furthermore that it proceeds pseudobarrierlessly in ISM-like ices.

\subsection{Astrophysical implications}

In the interstellar medium, $\mathrm{O}$ insertion pathways could be of particular importance in very cold regions where radical diffusion chemistry is not thermally accessible. Indeed, gas-phase chemistry leading to hydrocarbon formation is known to be very efficient at low temperatures; these hydrocarbons can then accrete onto grain surfaces. Meanwhile, as mentioned in Section 1, excited $\mathrm{O}\left({ }^{1} \mathrm{D}\right)$ atoms can be formed by energetic processing of common oxygen-bearing constituents of astrophysical ices (in particular, $\mathrm{H}_{2} \mathrm{O}$ and $\mathrm{CO}_{2}$ ). The insertion of oxygen atoms directly into hydrocarbons would then lead to the formation of a variety of complex organic species, without the need for radical diffusion. The degree to which this type of chemistry contributes to COM formation will need to be tested by astrochemical modelers. In this case, it will be important to distinguish between $\mathrm{O}\left({ }^{3} \mathrm{P}\right)$ and $\mathrm{O}\left({ }^{1} \mathrm{D}\right)$ atoms in order to accurately account for the chemistry.

Ultimately it will be important to quantify the process of $\mathrm{O}$ insertion into larger hydrocarbons: $\mathrm{CH}_{3} \mathrm{OH}$, while a convenient test case, can be produced in astrochemical models via $\mathrm{CO}$ hydrogenation. Larger organics, on the other hand, are regularly underproduced in models and therefore seemingly missing a formation pathway. From the limited literature available, $\mathrm{O}$ insertions into both saturated and unsaturated larger hydrocarbons should occur at low temperatures in condensed phases (Parnis et al. 1993; DeMore 1969), though further experiments are required to quantify the energetics and product distribution of such systems. While we expect to see a low or non-existent insertion barrier for larger hydrocarbons, it is important to obtain branching ratios for the insertion products: the $\mathrm{C}-\mathrm{H}$ bonds are not necessarily degenerate in larger hydrocarbons as they are in $\mathrm{CH}_{4}$, making it difficult to predict a priori which products will form. Moreover, gas-phase studies suggest that an abstraction channel becomes increasingly competitive with insertion for larger hydrocarbons (Luntz 1980). There is also some evidence for $\mathrm{O}$ insertion into $\mathrm{C}-\mathrm{C}$ bonds in the gas phase (Yang 2006). The experimental setup used in this study cannot be used to test oxygen insertions into other hydrocarbons, as most larger hydrocarbons have appreciable UV absorption cross-sections above the sapphire window cutoff; however, testing these systems experimentally should be possible with an atomic beam setup. Quantitative constraints on the energetics and product distributions of $\mathrm{O}$ atom insertion into larger hydrocarbons will enable an evaluation of the impor- tance of oxygen insertion chemistry to forming complex molecules in astrophysical environments.

\section{CONCLUSIONS}

We have experimentally tested and quantified the formation of $\mathrm{CH}_{3} \mathrm{OH}$ via oxygen insertion into methane in astrophysical ice analogs. From our results we conclude:

1. Selective dissociation of $\mathrm{O}_{2}$ in mixed $\mathrm{O}_{2}: \mathrm{CH}_{4}$ ices results in the formation of $\mathrm{CH}_{3} \mathrm{OH}$ in various isotopologue studies. The growth kinetics of $\mathrm{CH}_{3} \mathrm{OH}$ are well described by a model that includes both formation and photo-dissociative loss.

2. A direct insertion mechanism of $\mathrm{O}\left({ }^{1} \mathrm{D}\right)$ atoms into $\mathrm{CH}_{4}$ explains $\mathrm{CH}_{3} \mathrm{OH}$ formation, with a minor channel of $\mathrm{H}_{2} \mathrm{CO}$ production and no evidence of fragmentation to $\mathrm{CH}_{3}+\mathrm{OH}$. $\mathrm{O}\left({ }^{1} \mathrm{D}\right)$ insertions in ices therefore lead to a net increase in chemical complexity. We quantify the steady-state branching ratio to $\mathrm{CH}_{3} \mathrm{OH}$ to be $60-71 \%$.

3. Experiments with varying ice thicknesses and reactant ratios show no temperature dependence to the $\mathrm{CH}_{3} \mathrm{OH}$ formation rate constant $k_{r}$ from 9$24 \mathrm{~K}$. This holds even when the reactants are diluted in a $\mathrm{CO}$ matrix, consistent with a small or non-existent energy barrier to insertion.

4. Experimental constraints on the energetics and branching ratios of $\mathrm{O}$ insertions into larger hydrocarbons are required to assess the contribution of oxgyen insertion chemistry to observed abundances of COMs.

The authors thank Edith Fayolle, Robin Garrod, and Ilsa Cooke for valuable feedback. J.B.B acknowledges funding from the National Science Foundation Graduate Research Fellowship under Grant DGE1144152. K.I.O. acknowledges funding from the Simons Collaboration on the Origins of Life (SCOL) investigator award.

Software: emcee (Foreman-Mackey et al. 2013)

\section{APPENDIX A: IR SPECTRUM FITTING WITH MCMC}

For ${ }^{16} \mathrm{O}_{2}:{ }^{13} \mathrm{CH}_{4}$ experiments, each IR spectrum was fit from $940-1090 \mathrm{~cm}^{-1}$. The scan immediately prior to irradiation was subtracted from each irradiation spectrum. Irradiation spectra were then fit with a model consisting of a linear baseline term and four Gaussians:

$$
\begin{aligned}
& y(x)=y_{o}+m\left(x-x_{o}\right)+a_{1} e^{-\left(x-b_{1}\right)^{2} / 2 c_{1}^{2}}+ \\
& a_{2} e^{-\left(x-b_{2}\right)^{2} / 2 c_{2}^{2}}+a_{3} e^{-\left(x-b_{3}\right)^{2} / 2 c_{3}^{2}}+a_{4} e^{-\left(x-b_{4}\right)^{2} / 2 c_{4}^{2}}
\end{aligned}
$$


where $y_{o}$ and $x_{o}$ represent the $\mathrm{y}$ and $\mathrm{x}$ offsets for the baseline, $a_{n}$ are the Gaussian amplitudes, $b_{n}$ are the Gaussian centers, and $c_{n}$ are the Gaussian widths. An example corner plot from MCMC fitting with emcee is shown in Figure 9; for clarity, the fit parameters for two Gaussians are shown rather than all 16 parameters simultaneously. For fitting the ${ }^{18} \mathrm{O}_{2}: \mathrm{CD}_{4}$ experiments, the wavelength range used for fitting was $900-965 \mathrm{~cm}^{-1}$, and only two Gaussians were required in the model since the ${ }^{18} \mathrm{O}_{3}$ feature is sufficiently wellseparated from $\mathrm{CD}_{3}^{18} \mathrm{OD}$. For $\mathrm{CO}:{ }^{16} \mathrm{O}_{2}:{ }^{13} \mathrm{CH}_{4}$ experiments, spectra were fit from $980-1030 \mathrm{~cm}^{-1}$ and due to low product yields a single Gaussian was sufficient to fit the $\mathrm{CH}_{3} \mathrm{OH}$ feature.

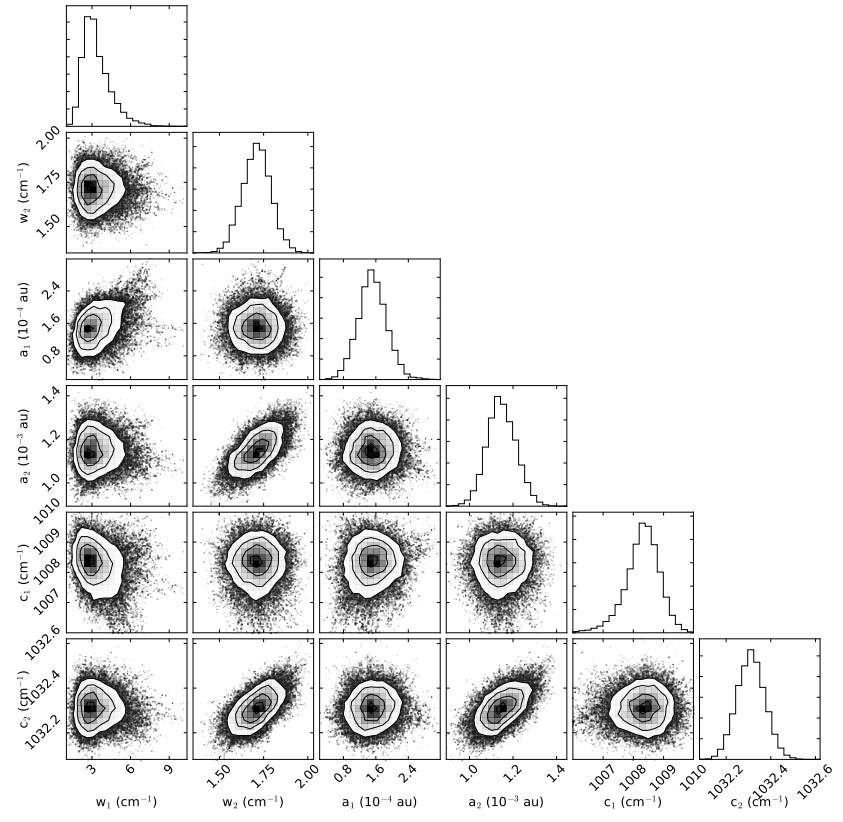

Figure 9. Example corner plot showing the covariance of two Gaussians used to fit the spectrum shown in Figure 2a.

\section{APPENDIX B: EXPERIMENTAL GROWTH CURVES AND MODEL FITS}

Growth curves along with best-fit kinetic models for all experiments are shown in Figure 10.

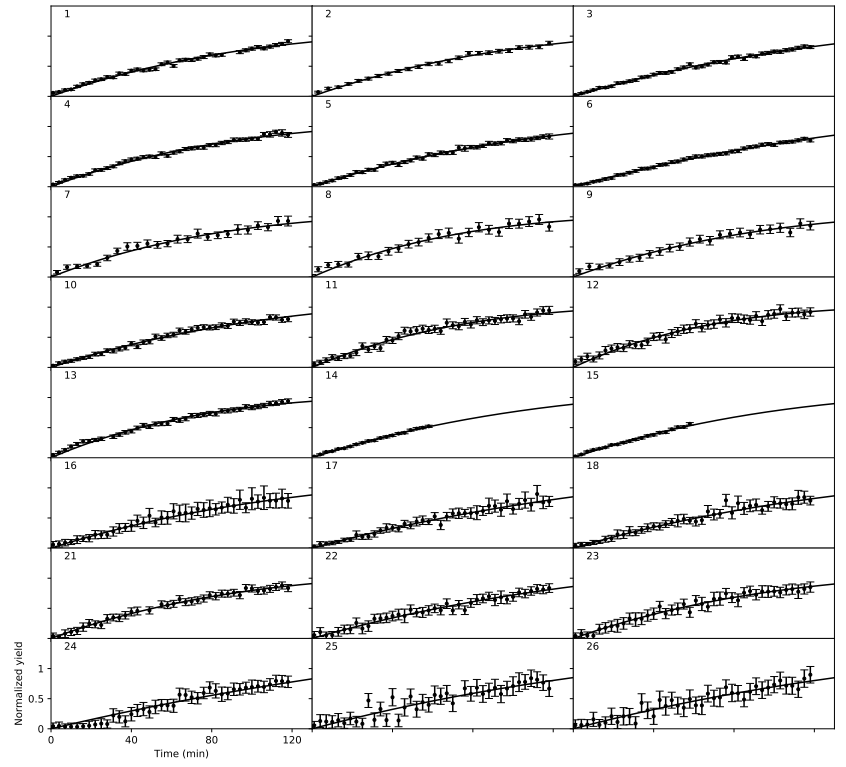

Figure 10. Experimental growth curves with best-fit kinetic models for all experiments. Experiment numbers from Table 1 are listed in each subplot.

\section{REFERENCES}

Appelman, E. H., Downs, A. J., \& Gardner, C. J. 1989, JPhCh, 93, 598
Arce, H. G., Santiago-García, J., Jørgensen, J. K., Tafalla, M., \& Bachiller, R. 2008, ApJL, 681, L21 
Bacmann, A., Taquet, V., Faure, A., Kahane, C., \& Ceccarelli, C. 2012, A\&A, 541, L12

Bennett, C. J., Chen, S.-H., Sun, B.-J., Chang, A. H. H., \& Kaiser, R. I. 2007, ApJ, 660, 1588

Bennett, C. J., \& Kaiser, R. I. 2005, ApJ, 635, 1362

Blake, G. A., Sutton, E. C., Masson, C. R., \& Phillips, T. G. 1987, ApJ, 315, 621

Bottinelli, S., Ceccarelli, C., Lefloch, B., et al. 2004, ApJ, 615, 354

Bouilloud, M., Fray, N., Bénilan, Y., et al. 2015, MNRAS, 451, 2145

Cernicharo, J., Marcelino, N., Roueff, E., et al. 2012, ApJL, 759, L43

Chang, A. H. H., \& Lin, S. H. 2002, CPL, 363, 175

Chuang, K.-J., Fedoseev, G., Ioppolo, S., van Dishoeck, E. F., \& Linnartz, H. 2016, MNRAS, 455, 1702

Cosby, P. C. 1993, JChPh, 98, 9560

Cruz-Diaz, G. A., Muñoz Caro, G. M., Chen, Y.-J., \& Yih, T.-S. 2014a, A\&A, 562, A119

Cruz-Diaz, G. A., Muñoz Caro, G. M., Chen, Y.-J., \& Yih, T.-S. 2014b, A\&A, 562, A120

DeMore, W. B. 1969, JPhCh, 73, 391

DeMore, W. B., \& Raper, O. F. 1966, JChPh, 44, 1780

DeMore, W. B., \& Raper, O. F. 1967, JChPh, 46, 2500

Du, J., Wan, L., Wu, L., et al. 2011, JPCA, 115, 1040

Dulieu, F., Amiaud, L., Congiu, E., et al. 2010, A\&A, 512, A30

Fayolle, E. C., Bertin, M., Romanzin, C., et al. 2013, A\&A, 556, A122

Fedoseev, G., Cuppen, H. M., Ioppolo, S., Lamberts, T., \& Linnartz, H. 2015, MNRAS, 448, 1288

Foreman-Mackey, D., Hogg, D. W., Lang, D., \& Goodman, J. 2013, PASP, 125, 306

Fuchs, G. W., Cuppen, H. M., Ioppolo, S., et al. 2009, A\&A, 505,629

Garrod, R. T., Widicus Weaver, S. L., \& Herbst, E. 2008, ApJ, 682,283

Garrod, R. T., \& Pauly, T. 2011, ApJ, 735, 15

Gerakines, P. A., Schutte, W. A., \& Ehrenfreund, P. 1996, A\&A, 312,289

Hays, B. M., Wehres, N., DePrince, B. A., et al. 2015, CPL, 630, 18

Herbst, E., \& van Dishoeck, E. F. 2009, ARA\&A, 47, 427

Hudson, R. L., Gerakines, P. A., \& Moore, M. H. 2014, Icar, 243, 148

Ioppolo, S., Cuppen, H. M., Romanzin, C., van Dishoeck, E. F., \& Linnartz, H. 2008, ApJ, 686, 1474

Kaiser, R. I., Maity, S. J., \& Jones, B. M. 2015, Angewandte Chemie, 127, 197

Kedzierski, W., Hein, J. D., Tiessen, C. J., et al. 2013, Can. J. Phys., 91, 1044

Lauck, T., Karssemeijer, L., Shulenberger, K., et al. 2015, ApJ, 801,118
Lee, L. C., Slanger, T. G., Black, G., \& Sharpless, R. 1977, $\mathrm{JChPh}, 67,5602$

Legay-Sommaire, N., \& Legay, F. 1982, CP, 66, 315

Lin, C. L., \& DeMore, W. B. 1973, JPhCh, 77, 863

Loeffler, M. J., Teolis, B. D., \& Baragiola, R. A. 2006, JChPh, 124,104702

Luntz, A. C. 1980, JChPh, 73, 1143

Lugez, C., Schriver, A., Levant, R., \& Schriver-Mazzouli, L. 1994, CP, 181, 129

Madzunkov, S., Shortt, B. J., MacAskill, J. A., Darrach, M. R., \& Chutjian, A. 2006, PhRvA, 73, 020901

Minissale, M., Congiu, E., Manicò, G., Pirronello, V., \& Dulieu, F. 2013, A\&A, 559, A49

Mohammed, H. H. 1990, JChPh, 93, 412

Nee, J. B., \& Lee, P. C. 1997, JPCA, 101, 6653

Öberg, K. I. 2016, ChRv, 116(17), 9631

Öberg, K. I., Boogert, A. C. A., Pontoppidan, K. M., et al. 2011, ApJ, 740, 109

Öberg, K. I., Bottinelli, S., Jørgensen, J. K., \& van Dishoeck, E. F. 2010, ApJ, 716, 825

Öberg, K. I., Garrod, R. T., van Dishoeck, E. F., \& Linnartz, H. 2009, A\&A, 504, 891

Öberg, K. I., Guzmán, V. V., Furuya, K., et al. 2015, Nature, 520, 198

Parnis, J. M., Hoover, L. E., Fridgen, T. D., \& Lafleur, R. D. 1993, JPhCh, 97, 10708

Romanzin, C., Ioppolo, S., Cuppen, H. M., van Dishoeck, E. F., \& Linnartz, H. 2011, JChPh, 134, 084504

Schriver-Mazzuoli, L., de Saxc, A., Lugez, C., Camy-Peyret, C., \& Schriver, A. 1995, JChPh, 102, 690

Sivaraman, B., Mebel, A. M., Mason, N. J., Babikov, D., \& Kaiser, R. I. 2011, PCCP, 13, 421

Slanger, T. G., \& Black, G. 1971, JChPh, 54, 1889

Slanger, T. G., \& Black, G. 1982, JChPh, 77, 2432

Stief, L. J., Payne, W. A., \& Klemm, R. B. 1975, JChPh, 62, 4000

Straub, H. C., Renault, P. Lindsay, B. G., Smith, K. A., \& Stebbings, R. F. 1996, PhRvA, 54, 2146

Straub, H. C., Lin, D. Lindsay, B. G., Smith, K. A., \& Stebbings, R. F. 1997, JChPh 106, 4430

Thomas Jr., S. G., \& Guillory, W. A. 1973, JPhCh, 77, 2469

Ung, A. Y. M. 1974, CPL, 28, 603

Walch, S. P., \& Dunning Jr., T. H. 1980, JChPh, 72, 3221

Watanabe, N., \& Kouchi, A. 2002, ApJL, 571, L173

Yang, X. 2006, PCCP, 8, 205

Yu, H., \& Muckerman, J. T. 2004, JPCA, 108, 8615

Zhao, H., Wang, W., \& Zhao, Y. 2016, JPCA, 120, 7589

Zheng, W., Kim, Y. S., \& Kaiser, R. I. 2011, PCCP, 13, 15749

Zhu, Y. F., \& Gordon, R. J. 1990, JChPh, 92, 2897 